\title{
Structure and function relationships of the helical ventricular myocardial band
}

\author{
Gerald Buckberg, MD, ${ }^{\mathrm{a}, \mathrm{b}}$ Aman Mahajan, MD, PhD, ${ }^{\mathrm{c}}$ Saleh Saleh, MD, ${ }^{\mathrm{d}}$ Julien I. E. Hoffman, MD, \\ and Cecil Coghlan, $M D^{f}$
}

Supplemental material is available online.
From the Option on Bioengineering, California Institute of Technology, ${ }^{\text {a }}$ Pasadena, Calif; Departments of Cardiothoracic Surgery, ${ }^{\mathrm{b}}$ Anesthesiology, ${ }^{\mathrm{c}}$ and Medicine, ${ }^{\mathrm{d}} \mathrm{Da}$ vid Geffen School of Medicine at UCLA, Los Angeles, Calif; Department of Pediatrics and Cardiovascular Research Institute, University of California, San Francisco, ${ }^{\text {e }}$ San Francisco, Calif; and Division of Cardiovascular Diseases, University of Alabama at Birmingham, ${ }^{\mathrm{f}}$ Birmingham, Ala.

Received for publication June 29, 2007; revisions received Aug 29, 2007; accepted for publication Oct 19, 2007.

Address for reprints: Gerald Buckberg, MD, UCLA Medical Center, Department of Cardiothoracic Surgery, Rm 62-258 CHS, Box 951741, Los Angeles, CA 90095-1741.

J Thorac Cardiovasc Surg 2008;136:578-89 $0022-5223 / \$ 34.00$

Copyright $(2008$ by The American Association for Thoracic Surgery

doi:10.1016/j.jtcvs.2007.10.088
Objective: Understanding cardiac function requires knowledge of the architecture responsible for the normal actions of emptying and filling. Newer imaging methods are surveyed to characterize directional (narrowing, shortening, lengthening, and widening) and twisting motions.

Methods: These movements are defined and then compared with a spectrum of models to introduce a useful "functional anatomy" that explains cardiac spatial and temporal relationships. The sequential nature of normal contraction differs from a synchronous beat.

Results: The prior concept of constriction is replaced by understanding that clockwise and counterclockwise helical motions are necessary to cause the predominant twisting motion. The helical ventricular myocardial band model of Torrent-Guasp fulfills the architectural structure to define normal function. Expansion of information from this model allows novel understanding of mechanisms that explains why a component of ventricular suction involves a systolic event, clarifies septum function, determines diastolic dysfunction, introduces new treatments, shows how knowledge of the helical structure influences understanding of atrioventricular and biventricular pacing, and creates novel methods for introducing septal pacing stimuli.

Conclusion: Further testing of these spatial anatomic concepts is needed to create a more accurate understanding of the architectural mechanisms that underlie cardiac dynamics to address future problems in unhealthy hearts.

$\mathrm{T}$ The classic article on structure and function was written in 1918 by Arthur Keith, ${ }^{\mathrm{E} 1}$ in which he stated that William Harvey realized more fully than any anatomist that structure is a pure guide to function. Harvey was a student of Fabricius in Padua, who studied anatomy to determine the purpose of the various parts of the human body. Harvey fulfilled the terms of a "functional anatomist," defined by Fabricius, and Keith stated there could be no greater mistake than to condemn these methods. These observations have enormous impact on the cardiac surgeon, because rebuilding the macroscopic structure/function relationship forms the infrastructure for our specialty.

Keith ${ }^{\mathrm{E} 1}$ elaborated on the recognized physiologic cardiac function and presented a currently unfulfilled challenge by stating "we cannot claim to have mastered the mechanism of the human heart until we have a fundamental explanation of its architecture." William Harvey dissected cadaver hearts and concluded that the heart squeezed by constriction to eject and dilated passively to fill. These basic concepts are the currently accepted mechanism of cardiac function, but they do not explain the twisting phenomena observed during emptying and filling of the viable beating heart that are seen during cardiac operations (Video 1) and that are now documented by magnetic resonance imaging (MRI) and speckle tracking echocardiography. ${ }^{1,2}$ 


\section{Abbreviations and Acronyms}

HVMB = helical ventricular myocardial band

$\mathrm{LV} \quad=$ left ventricle (left ventricular)

MRI = magnetic resonance imaging

$\mathrm{RV} \quad=$ right ventricle (right ventricular)

The heart is a muscular pump that supplies blood containing oxygen and nutrients to the body. This goal is achieved by electrical excitation that produces sequential ventricular emptying and filling. Figure E1 demonstrates the physiologic sequence of ventricular function: a contraction phase to develop pre-ejection tension, ejection, and rapid and slowperiods for filling. This report relates the function to the underlying precisely described muscular anatomy, thereby providing novel structural explanations for the contractile sequence that causes the ventricular directional motions of narrowing, shortening, lengthening, widening, and twisting (Figures 1, E2, and E3).

\section{Materials and Methods}

\section{Basic Ventricular Function}

The observed functional patterns (Figure 1) include an initial counterclockwise twist and attendant narrowing or "cocking" in the contraction phase before ejection, ${ }^{3, \mathrm{E} 2}$ followed by twisting of the cardiac apex in counterclockwise directions and the base in clockwise directions as the ventricle longitudinally shortens during the ejection phase, and a vigorous untwisting of the apex and base in a clockwise direction as the ventricle lengthens and slightly widens during a phase interval when no blood enters or leaves the ventricular chamber. This untwisting motion continues into the rapid filling interval, ${ }^{4, \mathrm{E} 3}$ and finally a phase of relaxation occurs during diastole when heart widening continues by slower filling, before the atrium contracts and before the next organized beat.

\section{Structural Mechanisms Underlying Ventricular Function}

The heart requires an architectural design that allows the contractile apparatus to empty and fill with optimal mechanical efficiency, determined by integration of vectors of force generated by sarcomeres that can only shorten by active contraction. Ventricular thickening increases approximately $50 \%$ for only approximately $13 \%$ of myocyte shortening, ${ }^{\mathrm{E} 4}$ so that structural changes in deformation create strain relative to fiber orientation and play an important role in explaining these findings. Mathematic modeling studies by Sallin $^{5}$ demonstrated that fibers with transverse orientation yielded an ejection fraction of $30 \%$, whereas an ejection fraction of $60 \%$ occurred if oblique orientation existed. The extracellular collagen matrix of the myocardium is an important scaffold in maintaining muscle fiber alignment, ventricular shape, and size. It forms a spiral fibrillar structure of endomysial collagen ${ }^{6}$ to support a spatial distribution of myocytes and myofibers that ensheath ${ }^{\mathrm{E} 5}$ the adjacent 3-dimensional reciprocal spiral arrangement pattern of muscle structure.

The networking of fibers with angulated connections to each other is an important observation by Anderson and colleagues, ${ }^{7}$ one that follows the suggestion by $\mathrm{Grant}^{8}$ and likely provides the structure behind the sequential action during the twisting motion. Moreover, the collagen weave network creating the connective tissue network or syncytium suggested by Grant in 1965 and shown by Lunkenheimer and colleagues in $1984^{\mathrm{E} 5}$ likely organizes the proper sheathing for the spiral muscle that runs within this collagen housing.

\section{Background of Structure and Function Observations}

Until recently, the concept of constriction for ejection and dilation for filling became the cardiodynamic guideline as a worldwide spectrum of anatomists searched for a structural form that creates this transverse squeezing motion. Such constriction contributed to the physiologic background for trying to recognize how myocytes are arranged to fulfill the functional observation by Otto Frank ${ }^{\mathrm{E} 6}$ in 1901, whereby coordinated systolic contraction was considered synchronous and unidirectional.

Clarifying the underlying cardiac structure has been a postmortem focus of anatomists for many years. In 1749, Senec suggested that the inner and outer coats of the left ventricle (LV) had a helical configuration, observations that followed the earlier descriptions of Lower in $1669 .{ }^{9}$ In 1790 , Weber suggested that the actions of the muscular heart would not be understood until the muscle bundles of the septum were clarified. In 1942, Robb and Robb ${ }^{9}$ summarized the concepts of 58 worldwide anatomists during 5 centuries, who agreed that the heart contained an oblique clockwise and reciprocally oblique counterclockwise muscle structure that sandwiched a circular transverse layer of muscle in the upper LV, believed to be responsible for the constriction thought to be responsible for systole. The natural cardiac sequential twisting motion was not observed or considered.

Yardsticks for structure/function approaches are evident from the classic anatomic observations of Krehl in $1891,{ }^{\text {E7 }}$ who described the "triebwerkzeug" for the circular fibers he observed at autopsy to accentuate LV systolic constriction, and the description of the "deep bulbospiral muscle" by MacCallum in $1901^{\mathrm{E} 8}$ (Figure 2, A) to explain this narrowing phase.

A myocardial syncytium without an obvious beginning or end that coordinates sequential motion was not considered by Anderson and colleagues ${ }^{7}$ and Grant. ${ }^{8}$ However, the reproducibility of these muscle bundle tracts was questioned by Grant ${ }^{8}$ and Lev and Simkins, ${ }^{10}$ and there was no effort to evaluate how this model explained the natural twisting motion of the working heart.

In 1953, Rushmer and colleagues ${ }^{11}$ looked at the whole ventricle mass, conceptually distinguished 3 layers of fibers (Figure 2, B), postulated that these fibers twisted into a vortex at the apex, and implied an intimate connection of individual muscle layers that they thought was impossible to demonstrate by dissection of a real heart. Rushmer and colleagues considered the transverse constrictor muscle responsible for ejection in their physiologic observations. They implied that a) simultaneous contraction of the oblique inner and outer muscles canceled each other out and that b) tension developed between them to generate "stored potential energy" to putatively establish diastolic recoil, which is currently thought to restore form during the rapid filling phase ${ }^{12}$ that follows what is now considered the "isovolumic diastolic relaxation" phase.

The landmark work of Streeter and colleagues ${ }^{13}$ in 1969 established the approximately 60-degree helical angular orientations of myocytes around the ventricular equator, which have been confirmed by magnetic tensor imaging recordings ${ }^{14}$ and by the recent 


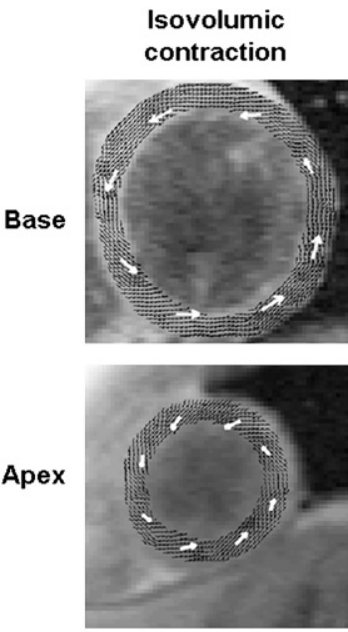

A
Ejection
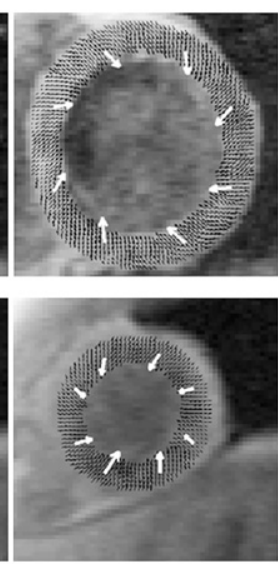

B
Rapid Filling
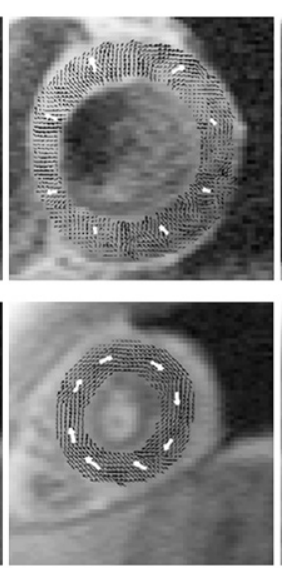

C
Slow Filling

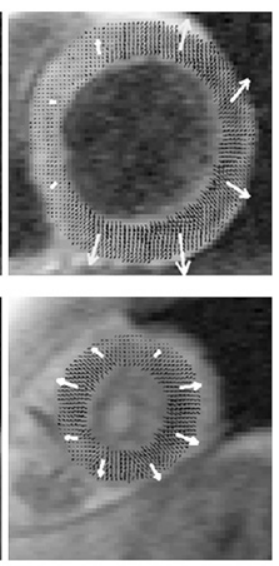

D
Figure 1. MRI phase-contrast velocity mapping (tissue phase mapping) of systolic and diastolic cardiac frames with a temporal resolution of $\mathbf{1 3 . 8} \mathbf{m s}$ during free breathing in a healthy volunteer. All motions are described in the text. The arrows show the clockwise (marker to right) and counterclockwise (marker to left) directions of twisting motion during the short-axis view and are obtained during contraction (A), mid-systole (B), rapid filling phase (C), and slower filling in mid-diastole (D). The 2-slice MRI positions of basal and apical regions demonstrating the twisting velocity directly correlate with speckle-tracking echocardiogram records shown in Figure 2. dissections of Jouk and colleagues. ${ }^{\text {E9 }}$ Circumferential ventricular histology sections from the LV base displayed a more transverse central fiber orientation than longitudinal sections toward the apex where only oblique endocardial and epicardial fiber orientation occurred, but the physiologic implications on LV mechanics for this differing structure were not defined. The underlying structural concept of Streeter and colleagues ${ }^{13}$ (Figure 2, C) was endorsed by Greenbaum and colleagues ${ }^{15}$ in 1981 , but they disagreed with the symmetric organization proposed by Rushmer and colleagues, ${ }^{11}$ invoking the principle that the dissection method may have disrupted muscle fascicles, which made it difficult to define the origin of the fibrous cardiac skeleton. Lunkenheimer and colleagues ${ }^{\mathrm{E} 10}$ recently emphasized the circular midventricular layer conceptually causing constriction for ejection and described different postmortem angulations from those described by Streeter. ${ }^{16}$

In 1957, Torrent-Guasp ${ }^{17,18, E 11}$ discovered a helical heart structure by simple hand dissection. First, the heart was unraveled to identify an underlying midventricular spiral fold that changed the transverse fibers to an oblique configuration and that allowed the unfolded heart to become a simple flattened longitudinal rope-like model extending from the pulmonary artery to the aorta (Figure 2, $D$ ). Refolding the heart into its natural biologic configuration allowed the definition of 2 loops, termed the "transverse basal" and "oblique apical loops" (Figure 3), providing a 3-dimensional spatial configuration called the "helical ventricular myocardial band" (HVMB). Torrent-Guasp's dissection introduced a "principal or dominant pathway" without defining individual fiber tracts. The resultant surrounding external basal loop buttress (or transverse shell embracing the right ventricle [RV] and LV) covered the internal oblique helical or conical apical loop comprising reciprocally oblique fibers termed the "descending and ascending segments," with a figure-of- 8 configuration that formed a vortex at the cardiac apex. These architectural findings mirror the anatomic suggestions in Rushmer and colleagues' cartoon ${ }^{11}$ (Figure 2,C) and concur with Grant's 8 rope-like model.

Recent 3-dimensional diffusion tensor MRI recordings ${ }^{19}$ (Figure E4) support the transverse basal loop with circular fibers described by many anatomists, together with the reciprocally oblique nature of the apical loop descending and ascending segment fibers, and demonstrate it involves the upper LV chamber without septum involvement to match the Torrent-Guasp dissection.

\section{Link Between Function and Anatomy}

Functional observations are the keynote link between structure and performance, because newer imaging modalities permit noninvasive monitoring of performance in living hearts to thereby offset artifacts that are potentially introduced by invasive methods. ${ }^{\text {E12 }}$ Consequently, dynamic data are yielded that must be explained by the spatial temporal aspects of macroscopic form to clarify cardiac mechanics by accurately defining the relationship of cardiac architecture to ventricular function.

A parallel issue arises in regard to macroscopic and microscopic studies by anatomists and pathologists, because the fixation techniques themselves may impose changes that are not present in the functioning heart, as defined by the Heisenberg Uncertainty Principle. For this reason, the end point for structure/function studies must be consistent with the architectural configuration that explains natural performance. Einstein said "it is always the theory which decides what can be observed," but added "there must be harmony between theory and experiment. If there is disagreement, and if that disagreement persists, experiment becomes, as always, the final arbiter and the theory must be brought into agreement with the experiment."E13

These introductory comments survey several functional concepts that underlie the current interplay of understanding the relationships between anatomy and normal cardiac performance. Fulfilling this requirement should a) spotlight differences between constriction versus twisting and define if a syncytium exists; b) explain the septum configuration and its impact on function; c) determine whether the concept of potential energy and diastolic recoil exists to define mechanisms for ventricular suction for rapid filling, and determine how this influences diastolic dysfunction; and d) distinguish differences between synchronous contraction and sequential motion that create twisting, analyze how these movements are governed by spatial temporal architecture, and interpose these findings into the ventricular performance impact of pacing the atrium, ventricle, both ventricles, and septum. Successful creation of a unifying theme for macroscopic form that correlates with normal function will establish a framework for recognizing how disease affects performance. 

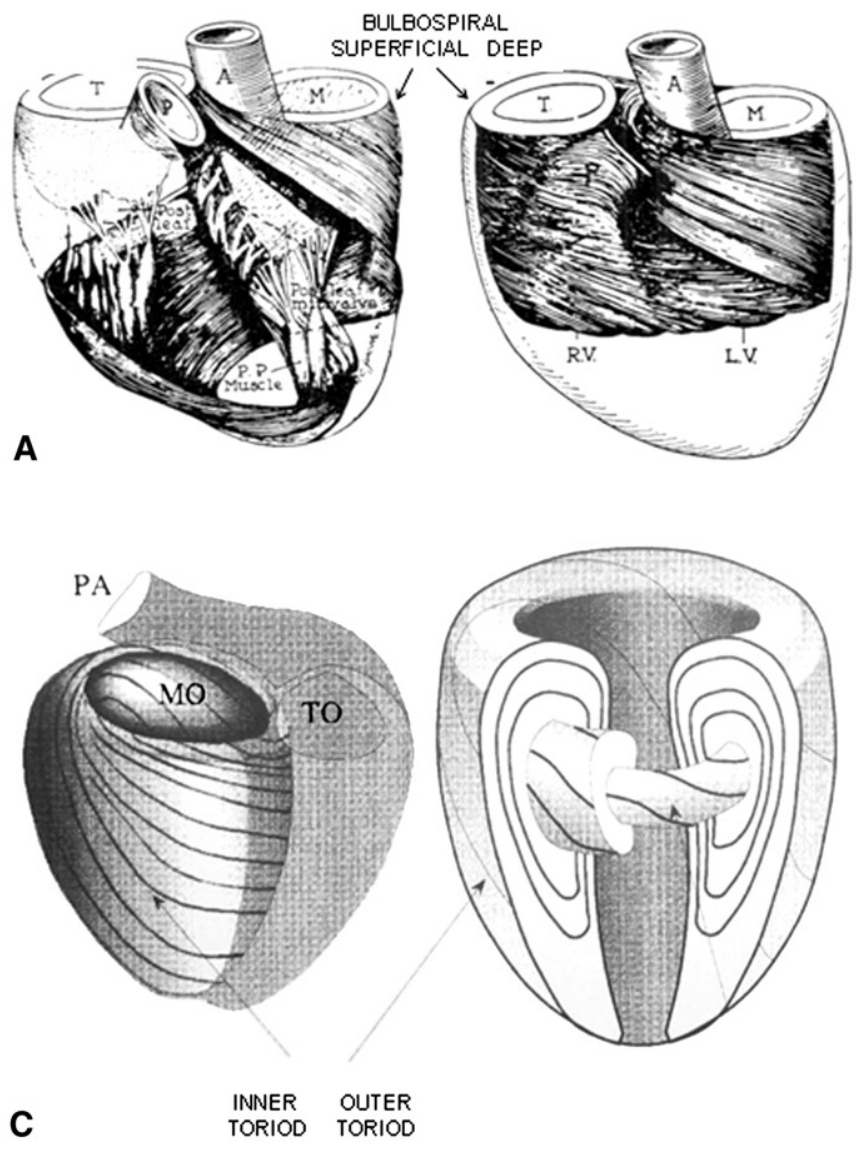
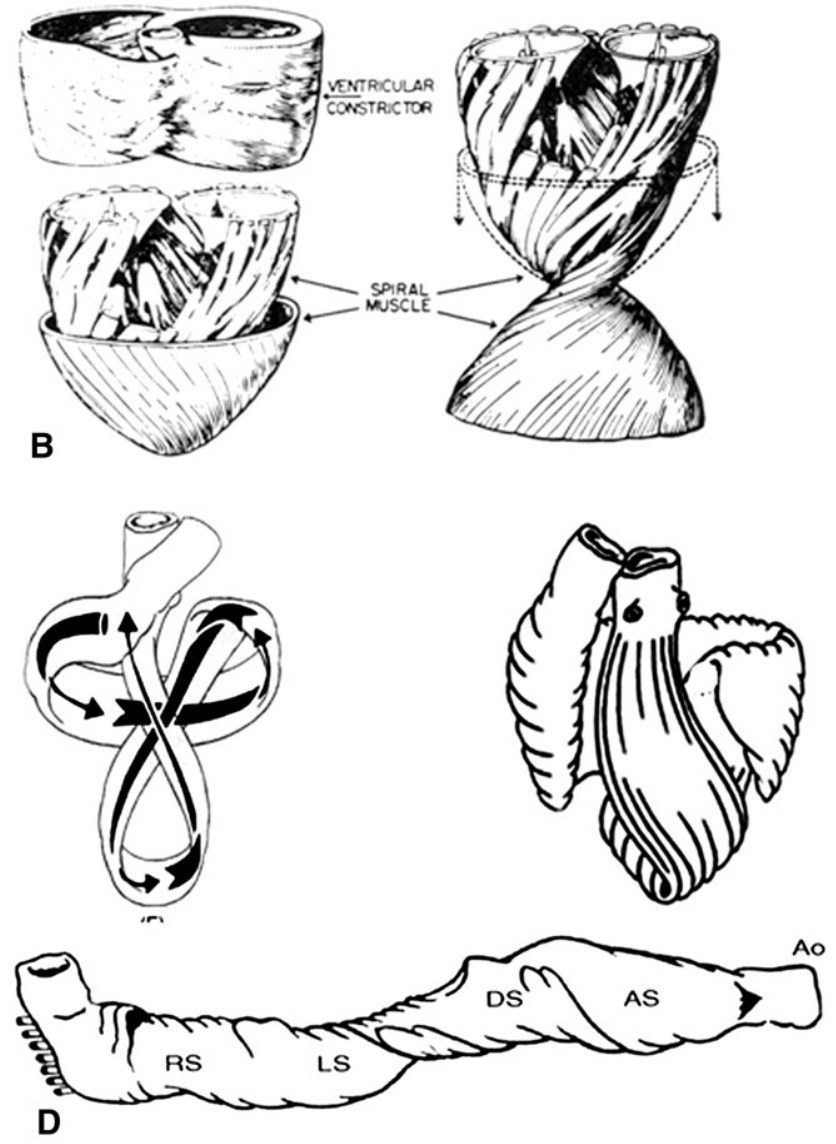

Figure 2. Examples of some models of myocardial fiber organization. A, Robb and Robb ${ }^{9}$ report the Mall and MacCallum suggestion of 4 myocardial bundles, with demonstration of deep (circular) and superficial oblique bulbospiral tracts. $A$, Aorta; $M$, mitral; $T$, tricuspid; $R V$, right ventricle; $L V$, left ventricle; pp, papillary muscles. B, Rushmer's conceptual model demonstrating how spiral superficial and deep clockwise and counterclockwise layers twist at the apex and sandwich the central constrictor muscle containing transverse circumferential fibers. C, Streeter's LV model in which inner and outer fibers run like geodesics (shortest path on curved surface) on toroidal surfaces (resembling doughnuts). The layers within another decrease in size as in Russian dolls. D, Torrent-Guasp's model in which the predominant fiber trajectory follows a pathway that contains an upper basal loop embracing (upper left) an internal helical loop. The anatomic display of these muscular components in the intact heart (upper right), whereby the upper transverse basal loop surrounds the oblique helical apical loop. This coiled arrangement is unfolded into a flattened rope model beginning at the pulmonary artery and ending at the aorta, whereby the right and left segments of the basal loop attach to the unwrapped apical loop containing descending and ascending segments. PA, Pulmonary artery; $R S$, right segment; $L S$, left segment; $D S$, descending segment; $A S$, ascending segment; Ao, aorta.

\section{Structure/Function Correlation}

The Torrent-Guasp anatomic data explain the manner in which the heart fills and empties. The predominantly transverse basal loop components are consistent with the circumferential muscular wrap showing strain movement from right to left that causes initial counterclockwise twisting and compresses the central apical loop like a stiff outer shell to narrow the mitral annulus during this preejection phase, ${ }^{\mathrm{E} 14}$ and with the horizontal basal fiber orientation displayed in Streeter's ${ }^{16}$ histology analysis. Early shortening of the circumferential base compresses the embraced apical loop and causes the temporary lengthening of the apex and base (Figure 4, A) during isovolumic contraction. This observation contradicts the apex to base motion of excitation contraction motion, ${ }^{2}$ because a circumferentially contracting and dominant basal loop that wraps around the apical loop provides a ready explanation of why the apex and base lengthen rather than shorten just before ejection and explains the "cocking" motion. ${ }^{\text {E15 }}$ Although the inner shell is stimulated at the earliest interval by the direct Purkinje/myocyte fiber connection, ${ }^{\mathrm{E} 16}$ there is insufficient transmural stimulation to cause longitudinal shortening at this time. The implications of the dominant force of the embracing basal segment are clear, because it is not possible for the stimulated and contracting descending segment 

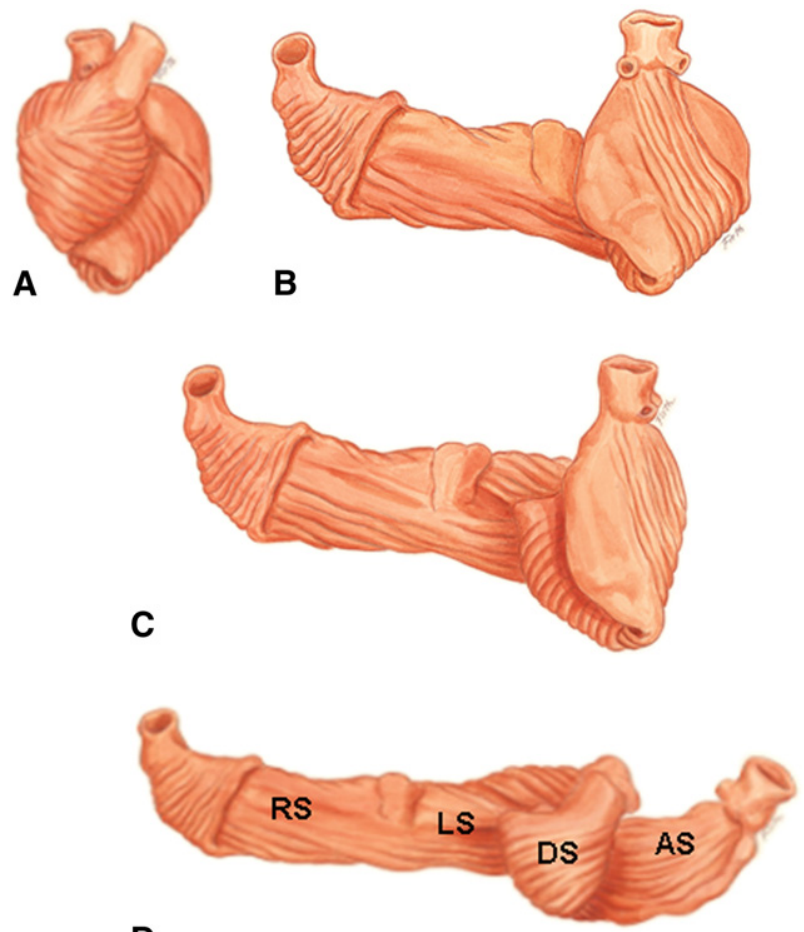

D

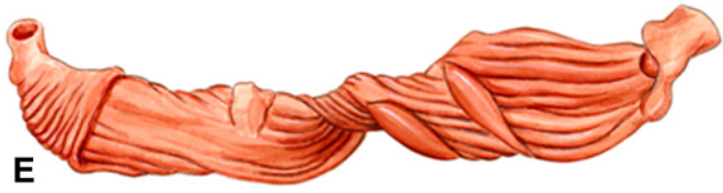

Figure 3. Unscrolling of Torrent-Guasp's myocardial band model, whereby the intact heart is unwrapped in (E) to define the stretched out band. Note the oblique fold in the center of the band that separates the basal and apical loops. Note also the transverse fiber orientation in the basal loop in (B-E), the helix of the apical loop that contains predominantly oblique fibers, with an apical reciprocal spiral as shown in (C), and the twisting nature of the helix at the junction of the basal and apical loops. The myocardial band extends between the pulmonary artery and the aorta. Note (A) the intact heart, (B) detachment of the RV free wall, or transverse orientation of right basal segment. A genu adjacent to the septum separates the RVs and LVs, (C) the detached rotated apical loop showing the left basal loop segment surrounding the inner helix configuration containing oblique descending and ascending segments, (D) unwrapping of the helix to show unfolding of the descending segment, and (E) the complete transverse myocardial band, with the central muscle fold to separate the basal and apical loops. The left segment is the transverse basal loop, containing left and right segments, and the right segment is the unwrapped apical loop containing a descending and ascending segment. $R S$, Right segment; $L S$, left segment; $D S$, descending segment; $A S$, ascending segment. to initially lengthen and then longitudinally shorten during ventricular emptying.

During ejection, the basal fibers continue to shorten at the same time that the oblique fibers shorten and thicken to become a counterforce that accentuates narrowing throughout emptying. Furthermore, contracting transverse basal fibers provide a "buttress" to counteract the outward forces generated by the twisting and shortening oblique muscle of the double helix of ascending and descending segments of the inner apical loop, and thereby prevent an outward explosion at the base during ejection. An opposite action exists in preparation for ventricular filling, when the oblique forces at the cardiac base are directed inward as reciprocal twisting develops an intraventricular vacuum for subsequent suction from unopposed lengthening via torsion of the ascending loop. The stiff outer rim basal wrap thereby retains the counterforce effect and thus prevents potential implosion of the base in the isovolumic phase with unopposed torsion action of the ascending segment. Consequently, the basal loop exerts the balancing action of preventing explosion during ejection and avoiding implosion before and during rapid filling, and has the predominant action of governing narrowing and widening motions.

During ejection, both segments are co-contracting and the surface epicardial (ascending segment) oblique fiber orientation is opposite the endocardial (descending segment) fiber orientation within a helical spiral fiber arrangement. The shortening motion during ejection reflects the dominant force of the descending segment, rather than the circumferential constrictor basal loop. This observation contradicts prior concepts about a) the importance of the central constrictor muscle during ejection and b) the larger oblique epicardial layer being the governing force during ejection. ${ }^{7, \mathrm{E} 17}$ The oblique spiral apical loop components of the descending and ascending segments are key determinants in the mechanism of the spiral strain underlying ventricular ejection and suction, and have a spatial and temporal relationship during the initiation and completion of their shortening.

Deformation is greatest toward the apex to achieve maximal reduction in chamber volume. ${ }^{20}$ The oblique descending muscle initiates shortening with the basal loop and is joined $80 \mathrm{~ms}$ later by cocontraction of a reciprocal fiber arrangement within the ascending segment of the apical loop that thickens and twists in an opposite direction (Figure 5; Video 2). The descending and ascending segments converge toward the apex and form a loop such that the small movement at the base translates into a larger motion at the apex, similar to focusing a beam of light by a lens. Furthermore, the descending segment maintains stiffness immediately after it stops contracting and thus may act as a fulcrum as the ascending segment continues to contract for approximately $90 \mathrm{~ms}$ more (Figure 5) to become the dominant force for lengthening.

An incorrect concept is the previously interpreted "isovolumic relaxation phase" after ejection, whereby the cardiac silhouette lengthens and slightly widens; this interval is a "contraction phase" ${ }^{, 21,22}$ because the lengthening is caused by ongoing contraction of the ascending segment that maintains active strain (Figure 6, $A$ ) as it thickens and elongates. This motion mirrors the spatial lengthening that exists when a cobra elongates as its muscles continue to contract in the interval before striking. Consequently, a muscular force causes lengthening, a finding that differs from the concept of "recoil from stored potential energy." This active muscular effort results in a lengthening and differs from the "untwisting" concept that is conventionally used. 


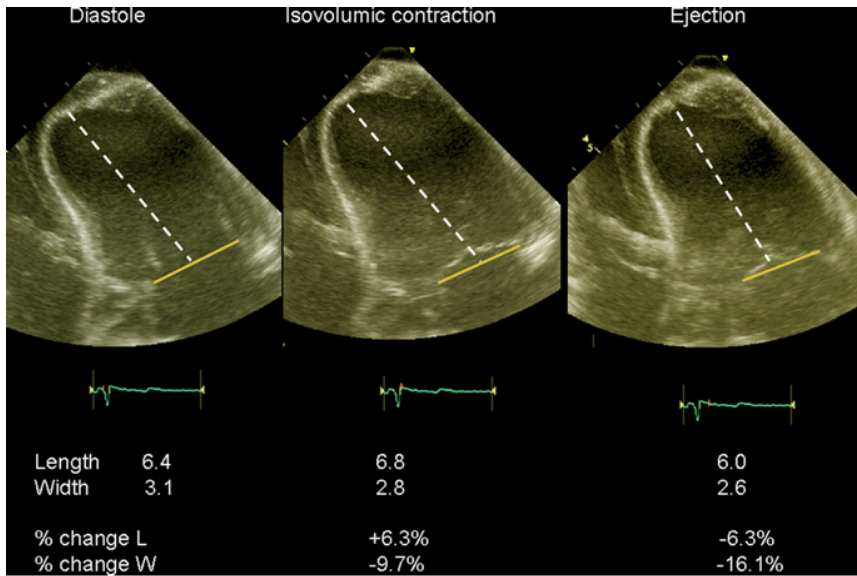

A

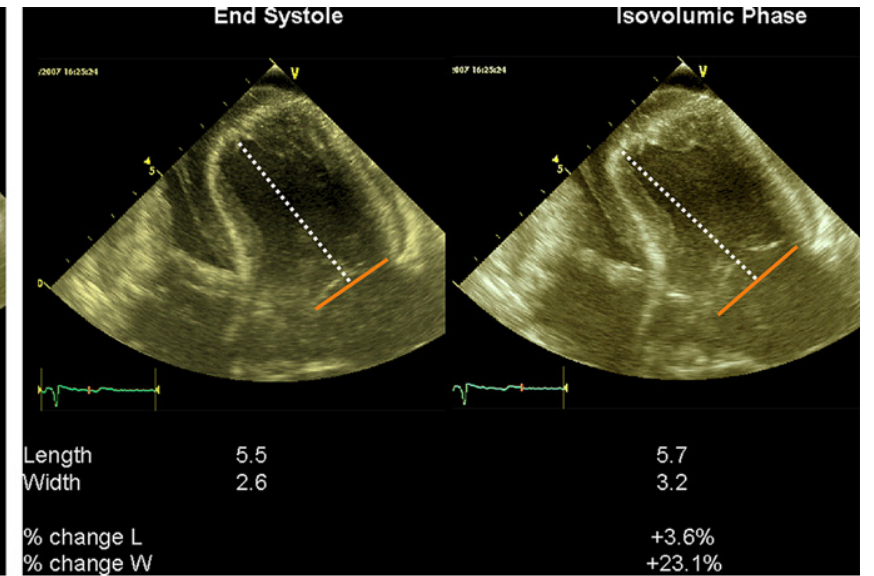

B

Figure 4. A, Two-dimensional imaging showing the change in length of the $L V$ cavity and width of the mitral annulus during diastole, contraction, and systolic ejection phases. The length and width line dimensions are measured and expressed numerically, and the percentage of change related to dimensions is recorded at the end of the diastolic filling phase. Note that the LV cavity lengthens and widens during the contraction phase and then shortens and narrows after ejection ensues. B, Changes in ventricular length and width between end systole (with mitral valve closed) and post-ejection interval. Note that the ventricular cavity lengthens, cardiac base widens as the mitral annulus increases diameter, and mitral valve opening begins despite no change in ventricular blood volume. The length and width line dimensions are measured and expressed numerically, and the percentage of change related to dimensions is measured in end systole, as observed in the marker on the electrocardiogram.

Ventricular widening during the isovolumic lengthening interval (Figure $4, B$ ) cannot be generated by the ascending segment, because it is the only segment still contracting; shortening has stopped in the right and left segments of the basal loop and the descending segment. Elastic recoil of compressed titin coils within the basal loop fibers is the most likely mechanism for generating this dilating or widening untwisting force that expands the cavity for subsequent rapid filling. ${ }^{23}$ Further widening during the rapid filling phase is caused by the introduction of elastic recoil from compressed titin in the ascending segment, which comes into play as contraction and strain stop in the ascending segment' together with accelerated entry of ventricular volume during this interval.

The contributions of different segments toward these 4 phases of physiologic motion response are identified by placing sonomicrometer crystals into the right and left segments of the basal loop, as well as into the descending and ascending segments of the apical loop of the LV free wall. ${ }^{22, E 18}$ During the pre-ejection contraction phase, shortening occurs in 3 regions of the right and left basal segments and the LV endocardium. With ejection, co-contraction exists in the descending and ascending segments, together with ongoing shortening of both basal loop segments, so that all 4 areas are shortening. Conversely, during the rapid filling intervals, active shortening occurs in only 1 ascending segment, because contraction has stopped in both segments of the basal loop and in the descending segment.

\section{Constriction Versus Twisting and a Syncytium}

The suggested syncytial properties of the cardiac muscle (coordinated and concomitant or synchronous contraction of muscles along their entire length) ${ }^{7, \mathrm{E} 19}$ cannot apply during systole in the working normal heart. One look at the living heart tells the whole story, because the sequential twisting shown in Videos 1 and 2 and MRI sequencing ${ }^{1}$ cannot occur if the excitation impulse is short-circuited to make all fibers contract together to constrict the cardiac chamber. Two-dimensional strain imaging by the speckle tracking method allows identification of longitudinal strain fields, ${ }^{24}$ and documents strain evolution (Figure 6,B). These observations confirm the presence of different "principal or dominant pathways" that work collaboratively and without the need to define individual fiber tracts.

Ultrasonic crystal tracings confirm spatial and temporal relationships of sequentially shortening fibers, and echocardiographic observations document the resultant thickening that follows cocontraction of the sequential ascending and descending segments (Figure 5). Conversely, the concept of a syncytium may apply to the noncontracting muscle during diastole, where the entire relaxed muscle must be in the same synchronous electrical state to set the stage for contraction during the next systolic beat.

The contrast between synchronous and sequential motion is also evident by experimentally or clinically comparing atrioventricular or ventricular pacing with atrial pacing. These observations follow Wiggers' observation in $1925^{\mathrm{E} 20}$ that asynchronous contraction results from interrupting of the normal sequential contraction pattern. Recent pressure dimension loop recordings after ventricular pacing support this consideration ${ }^{25}$ by displaying how dyssynchronous shortening interferes with the natural sequential curves existing after natural rhythm, produces constriction without twisting, and impairs cardiac performance.

\section{Septum}

The ventricular septum is a thick structure comprising discrete muscular bands that separate the LVs and RVs and contribute to cardiac 


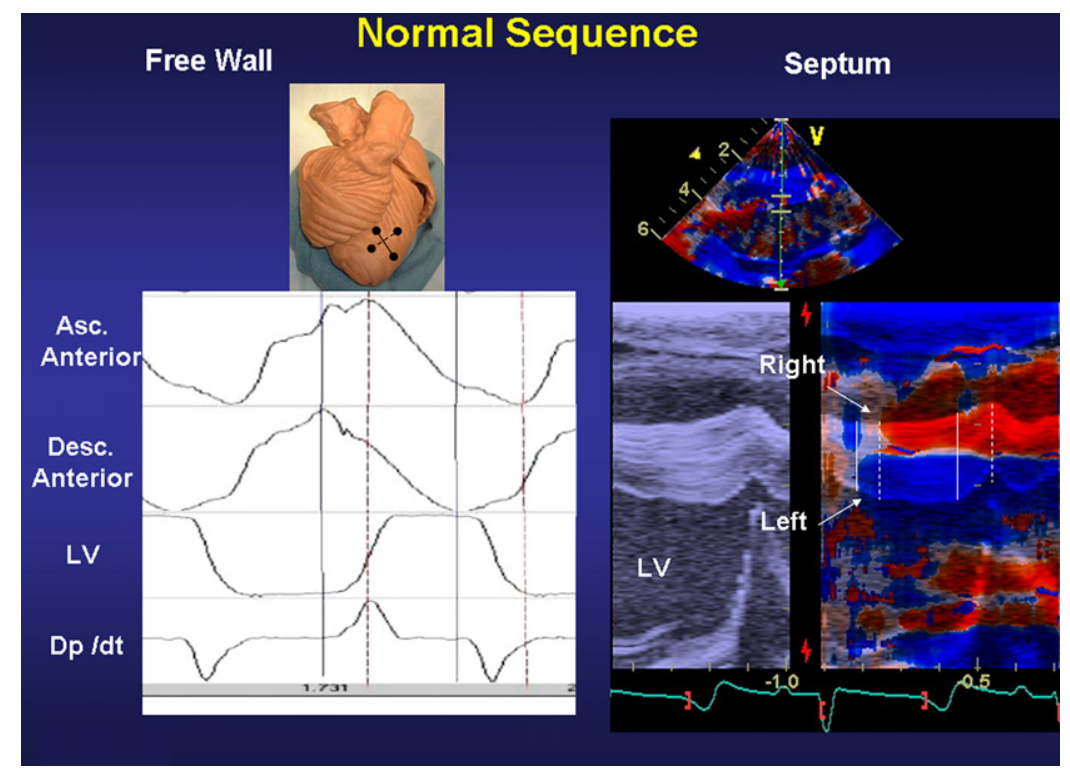

Figure 5. Comparison of ultrasonic crystal tracings of descending and ascending segments of LV free wall and M-mode and Doppler M-mode imaging of the septum. The beginning and end of descending segment shortening and motion (solid lines), and the ascending segment (hatched lines). Strain in the right (red) and left (blue) sides of the septum is noted in systole. M-mode shows displacement of the left and right sides of the septum toward their respective ventricular chambers. Note the delay of initiation of ascending segment and right septal motion and lengthening of descending segment during phase after ejection and continuing displacement of the right side of the septum toward the RV cavity, despite the beginning of LV cavity expansion. $L V$, Left ventricle.

function. Analysis of this structure/function relationship requires a full understanding of how anatomic form translates into hemodynamic performance, and satisfactory accomplishment of this task shall answer the 1790 supposition of Weber, ${ }^{\text {E21 }}$ who indicated that actions of muscular heart would not be understood until the muscle bundles of the septum are clarified.

Our initial experimental evaluation of septal structure/function relationships with sonomicrometer crystal measurements shows how fiber orientation determines the maximum rate of systolic shortening and validates the hypothesis that septum anatomy conforms to the descending and ascending segments of the ventricular myocardial band, as described by Torrent-Guasp and colleagues ${ }^{26}$ (Figures 7 and E5). This spatial composition has been recently supported by diffusion tensor MRI recordings (Figure 8). ${ }^{19,27}$ Oblique fibers of the endocardial regions of the left and right sides of the septum displayed the same functional characteristics that exist in the free LV wall and thereby confirm a comparable spatial structural configuration required to develop the twisting action that is essential for efficient cardiac output against higher pulmonary vascular resistance. ${ }^{28}$

The interaction between noninvasive methods and structure is enhanced by conventional low-resolution ultrasound imaging of the working ventricular septum, which has previously identified a hyperechogenic "septal line" (Figure 9, $A$ ) that matches the septal separation shown by postmortem contrast tomography studies by Lunkenheimer and colleagues ${ }^{\mathrm{E} 5}$ and runs in a basal-apical direction (Figure E6). Moreover, fibers in different directions, separated by a line, seem to cancel the syncytium concept if this conclusion was achieved by transmural biopsy; yet this term can only apply to the entire unfolded myocardial structure because the "line" in the septum and free wall only occurs after the unwound heart is refolded to the natural configuration achieved after evolution.

High-resolution ultrasound imaging allows identification of the structural and functional separation of the ascending and descending septum components along the previously observed "septal line," along with temporal and sequential movement of these muscle layers toward the respective ventricular cavities (Figure 9, $A$ and $B$; Video 3).
Visualization of different fiber orientation in the working heart using high-resolution echocardiography strongly supports the anatomic models displaying the muscle bands that form the ventricular septum. Recent animal studies in the working heart, using higher magnification of this septum midline in porcine and rabbit models, document that a space exists between the edges of the line (Figure 9, $B$ ). The line is approximately $100 \mu \mathrm{m}(0.10 \mathrm{~mm})$, and its thin-edge components attach to the overlying ascending and descending segments of the septum muscle. The septum muscle on either side of this line in the working hearts shows a relative uniformity that depends on the echocardiogram probe placement position in relation to fiber orientation planes that pass along or across working muscle (Figure 6, $B$ ). Further analysis of the midseptum line demonstrates that the space between its edges a) is retained during systole (when intramyocardial vessels are collapsed by the surrounding contracting muscle); b) is unchanged during early diastole (when flow through vessels is greatest and would expand the space if it was vascular); and c) becomes obliterated when function of the overlying ascending and descending segments is removed during cardiopulmonary bypass by inducing ventricular fibrillation or cardiac arrest by cardioplegia (Figure 9, $B$ ).

The space between this line conforms to the pathway followed by Torrent-Guasp during his cardiac dissection as he separated the ascending and descending loops during postmortem analysis. Most important, the collapse of this space between the border edges of this midseptal line precisely reflects the conditions encountered by the anatomist or pathologist in the cadaver or biopsy specimen. Structural differences between dead versus live conditions coexist, but matching form and performance must remain the goal of the functional anatomist.

We concur with problems related to cadaver dissection limitations that were suggested by Grant ${ }^{8}$ and Lev and Simkins, ${ }^{10}$ and that are now supported by Anderson and colleagues. ${ }^{7}$ An example is the incorrect posterior papillary muscle position that accompanies the myocardial band unfolding diagrams by Torrent-Guasp. ${ }^{\text {E22 }}$ Torrent-Guasp and colleagues realized this error when they were made aware of the 1971 functional studies by Armour and Randall. ${ }^{29}$ 


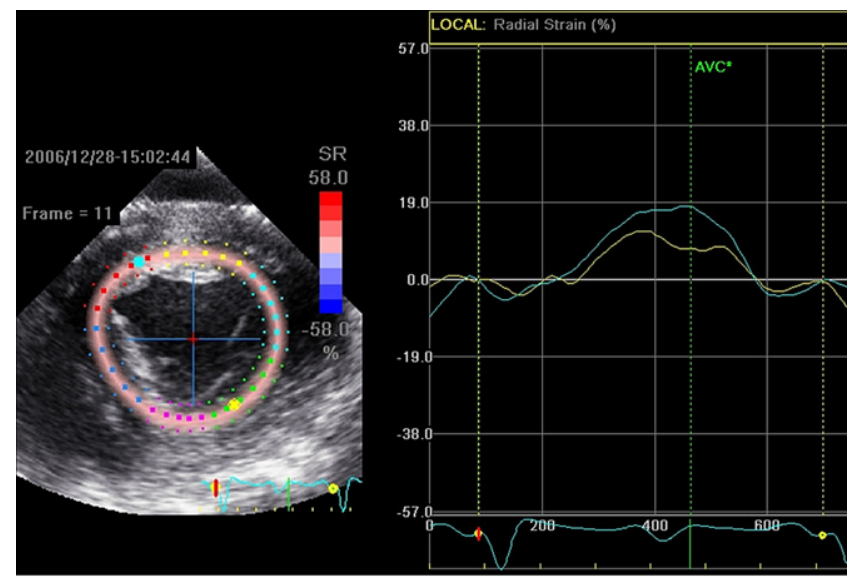

A

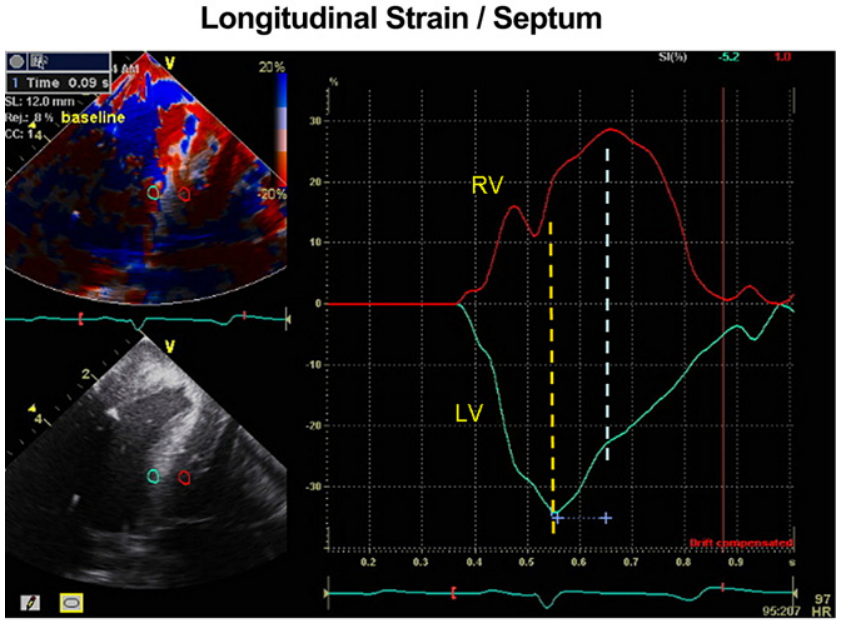

B

Figure 6. A, Two-dimensional strain imaging using speckle tracing showing strain (deformation) in the different segments of LV at the mid-papillary level. Strain in inferior-septal (green) and anterior-lateral (yellow) segments differs during different phases of cardiac cycle. The marker (aortic valve closure) signifies the end of the $T$ wave to define initiation of the interval after ejection. Strain persists during reciprocal twisting and extends into the next rapid filling phase characterized in Figure $2, B$. Strain is higher in anteroseptal than posterolateral segments. No relaxation (return to the zero line) exists during the rapid filling phase intervals. B, Doppler strain imaging of the right and left sides of the septum acquired in a modified apical 4-chamber view. Longitudinal strain or deformation curves during a cardiac cycle in the septum are measured in the region of interest marked by red (right) and green (left) circles. Longitudinal deformation occurs in opposite directions on the right and left sides of the septum, and the directionality difference is determined by displacement relative to the baseline zero value, as described in the text. $S R$, Strain rate; $A V C$, aortic valve closure; $R V$, right ventricle; $L V$, left ventricle.
Their subsequent dissections display the proper location, and they encouraged valid correlation of structure and function during efforts to understand architectural reasons for living heart motions. Claude Bernard ${ }^{\mathrm{E} 23}$ taught this orderly approach in the 1800 s because he was troubled about the dismissal of functional anatomy by those who study dead tissue and can only deduce function, rather than taking account of the living heart's observed actions.

The physiologic implications of these observations is that the oblique nature of the septum structure is a vital component needed for generating the twisting motion required for efficient ventricular ejection against increased peripheral vascular resistance. In contrast, constriction or bellows action is the predominant function of the basal loop as the result of its predominant transverse fiber orientation, because its circular fibers surround the LVs and RVs. Consequently, right-sided heart function may become impaired after loss of sequential septum contraction with attendant pulmonary hypertension, an effect that sometimes follows septum hypokinesia or akinesia in cardiac surgical procedures with impaired myocardial protection, after temporary ischemia, or when the septum is stretched after LV or RV volume overload. Conversely, recognizing and using knowledge from this form-function relationship has resulted in developing innovative RV reconstructive procedures that restore the septum into the midline position, recover its twisting action, and result in favorable clinical outcomes. ${ }^{30}$

\section{Ventricular Suction and Diastolic Dysfunction}

The traditional concept of diastole is to consider that this interval is composed of a period characterized by a fast decrease in ventricular pressure (from $120 \mathrm{~mm} \mathrm{Hg}$ to approximately zero after mitral valve opening), followed by a rapid-filling phase when atrial blood is sucked into the lower pressure and relaxing ventricle and then a subsequent slower filling interval. The time interval during which this initial pressure decrease occurs is approximately $120 \mathrm{~ms}$ in the normal human heart.

Active diastole was thought to relate to elastic recoil of surrounding connective tissues, ${ }^{4,12, \mathrm{E} 24}$ with suggestions that the elastic properties of connective tissues may release energy stored by the preceding systolic phase. ${ }^{31, \mathrm{E} 24, \mathrm{E} 25}$ No conclusive data have confirmed these elusive elastic properties of collagen or other connective tissues. Titin, a recently described protein myofilament, is thought to deform and provide some of the restoring force to the sarcomere, ${ }^{32,33}$ but the elastic response time (the time it takes to produce the relaxed length of sarcomere) of titin is too long to match the $120 \mathrm{~ms}$ duration of the isovolumic period during which the ventricular pressure decreases to $85 \%$ of its diastolic value.

Recent ultrasonic crystal studies of the ascending and descending segments of the HVMB have demonstrated the incorrectness of the term "isovolumic diastolic relaxation," because ongoing contraction ( $90 \mathrm{~ms}$ ) (Figure 5) of the ascending segment of the apical loop occurs during this interval. Echocardiographic studies demonstrate retention of muscle thickness, and the observed lengthening is related to ongoing strain during this "relaxation" interval (Figure 6, A). Consequently, the term "late systolic contraction" should replace "diastolic relaxation."

More important, temporary diastolic dysfunction follows prolongation of descending segment contraction in this structural/function counterpart. ${ }^{34}$ Such prolonged contraction disturbs suction by interrupting the natural hiatus of approximately $90 \mathrm{~ms}$ between the end of contraction of the descending segment and the ongoing unimpeded 


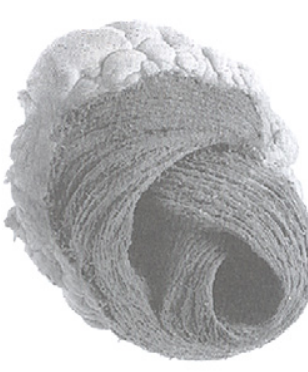

A

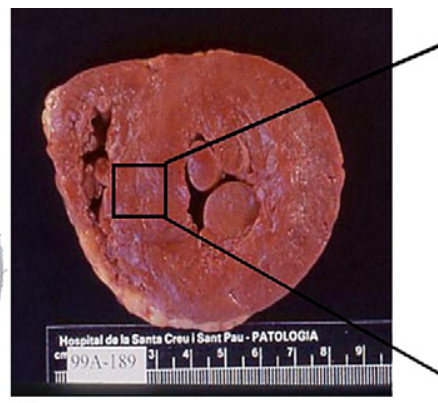

B

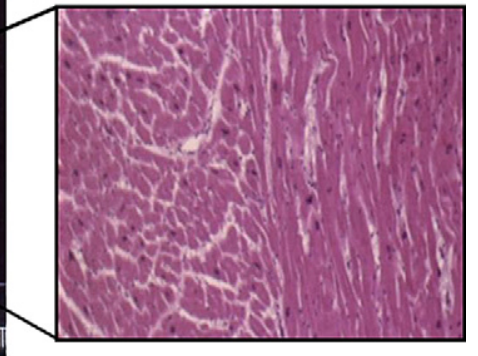

C
Figure 7. A, Torrent-Guasp cardiac dissection showing the septal separation between the ascending and descending segments of the apical loop, whereby the line between them conforms to the line seen by echocardiogram tracings. B, Cross-section of septum from report by Carreras showing the fibers going in different planes. C, Enlargement of this image showing the different fiber directions between these 2 layers. This junction reflects the septal plane that Torrent-Guasp demonstrated by unfolding the heart to separate the ascending and descending segments. Carrena F. Ballestor M. Pujadas S. Lata R. Pons-Llado G. Morphological and Functional evidence of the helical heart from non-invasive cardiac imaging. Eur. J. Cardiothoracic Surg. 2006 App;29 Suppl 1:550-5. ascending segment contraction (Figure E7). Such limitations prevent the lengthening, which is associated with untwisting to develop an intraventricular vacuum that may accelerate subsequent rapid filling. Furthermore ventricular stiffness increases from this structure/ function derangement to compromise rapid filling as the suction mechanism is derailed. Increased ventricular pressure then becomes the principal determinant of ventricular filling, rather than the natural ventricular untwisting and lengthening responsible for this physiologic sequence.

Experimental data has tested this concept by showing that limiting calcium flux by $\mathrm{Na}^{+}-\mathrm{H}^{+}$exchanger inhibitors reversed stunning-related diastolic dysfunction (Figure E8). ${ }^{34}$ Such observations open the door for consideration of a new spectrum of pharmacologic agents that either limit calcium entry $\left(\mathrm{Na}^{+}-\mathrm{H}^{+}\right.$exchanger inhibitors) or alter ionic calcium exchange efficiency (eg, levosimendan). ${ }^{\mathrm{E} 26}$ Recognition of a structure/function reason for diastolic dysfunction may have direct application a) after off-pump coronary bypass procedures for which a 10 to 15 -minute period of ischemia is routine; b) in on-pump procedures when cardioplegic protection is not adequate; and c) after congestive heart failure, when approximately $50 \%$ of patients have diastolic dysfunction despite retained systolic function. ${ }^{\text {E27 }}$

\section{Pacing and Synchronous Versus Sequential Contraction}

Atrioventricular pacing is conventionally used to treat bradycardia or heart block because of ease of implantation and electrical stability, but the previous discussion about synchronous versus sequential contraction showed that asynchronous electrical activation of myocyte shortening within the ventricular myocardial band by direct ventricular pacing disrupts the orderly sequential progression of shortening along the helical heart spatial configuration. ${ }^{25,35}$ This was demonstrated by placing sonomicrometer crystals along the correct trajectory of the muscle pathway (Figure E9 E10). Orderly sequential shortening of descending, posterior, and then ascending segments resulted in a normal progression of pressure-dimension loops and visible twisting of the cardiac silhouette (Figure E9).

Biventricular activation, termed "cardiac resynchronization therapy," is a novel recent treatment for failing ventricles with ${ }^{\mathrm{E} 28}$ and without ${ }^{\mathrm{E} 29}$ a wide QRS interval. This approach introduces

\section{MRI Tensor Imaging}

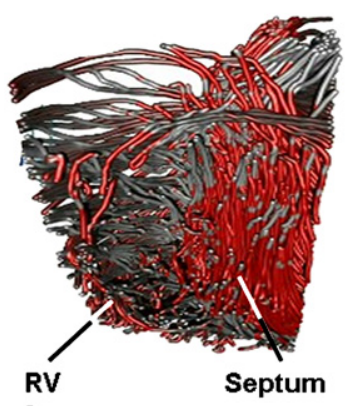

A

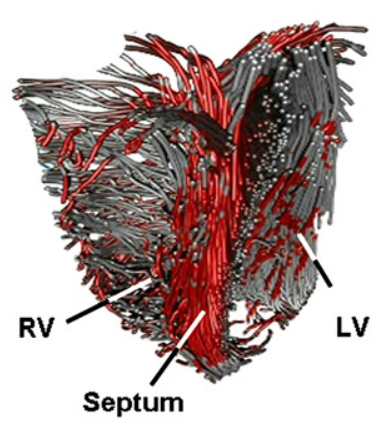

B

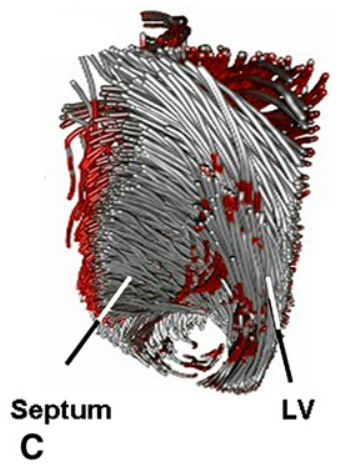

Figure 8. Fiber tracking performed in the LVs and RVs of the human heart using regularized tensor diffusion MRI visualization techniques. The geometry of the fibers of both RVs and LVs and the septum is shown, and the continuity of the LV fibers with the septum can be seen. The transverse fiber orientation of the RV free wall is also evident. A, RV and septum. B, Septum in a transverse view. C, Left side of septum. Note the fiber angulation mirrors the muscle fiber orientation in Figure 4. (Reprinted with permission from Lawrence National Berkeley Laboratory Publications.) RV, Right ventricle; $L V$, left ventricle. 


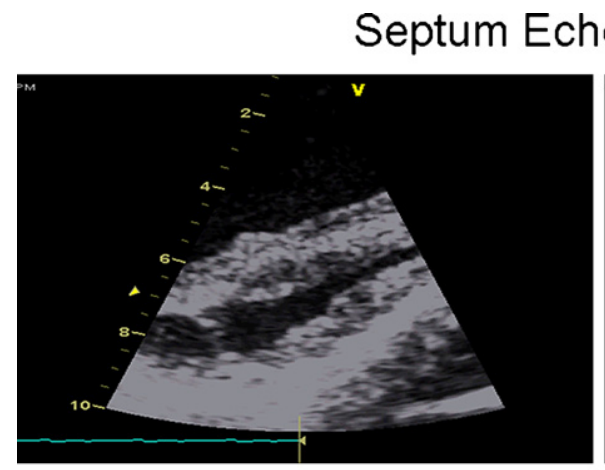

A

Low
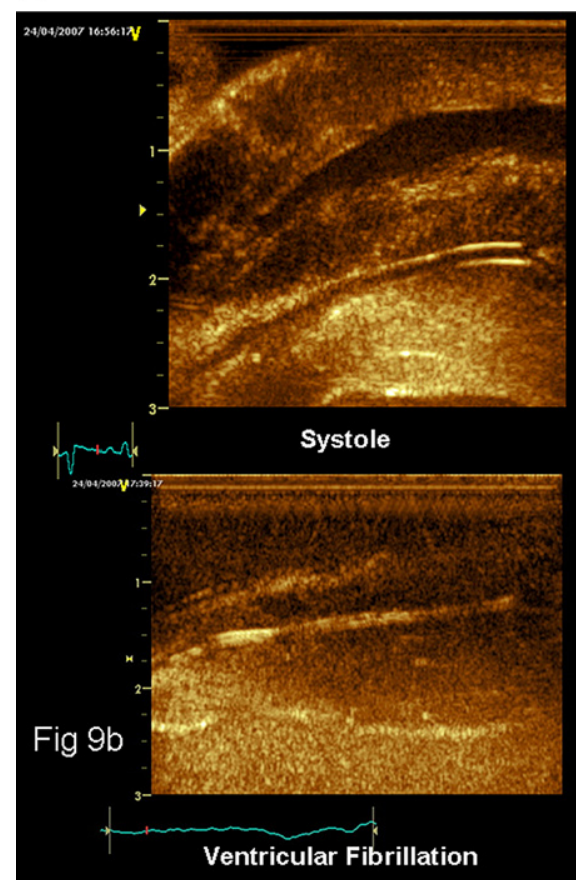

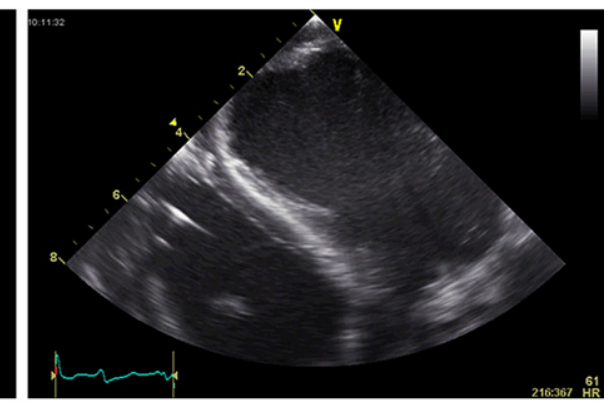

High

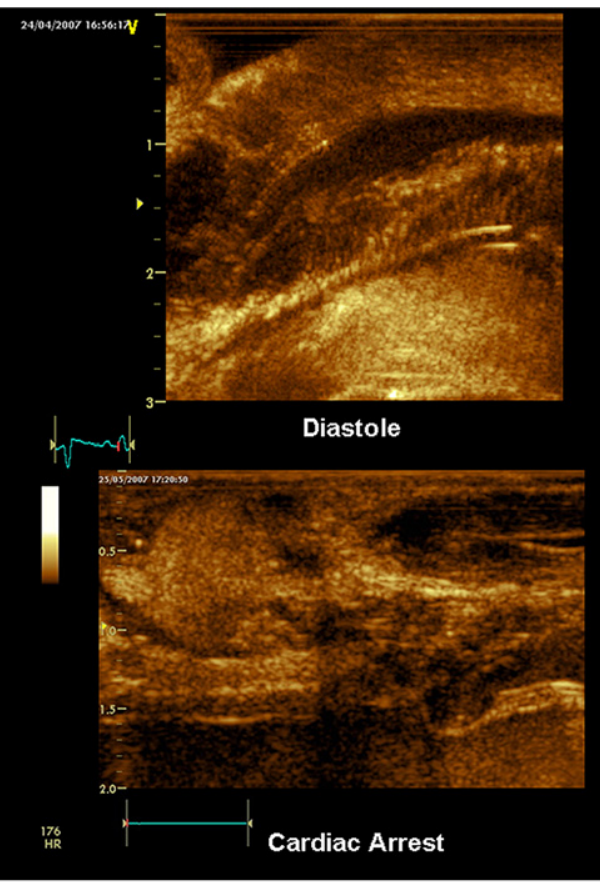

Figure 9. A, Low and high-resolution echocardiogram showing the midhyperechogenic and midseptal line. B, High-resolution ultrasound image of the septum at the base of the heart acquired using high ultrasound transducer frequency (12 MHz). Septal images showing a bilayer structure with an inner dimension of 100 to $150 \mu \mathrm{m}$. B-mode or echocardiographic pattern of the septum on either side of the septal bilayer is different, demonstrating the different directionality of the myocardial fibers on the respective sides of the septum. The septal bilayer is recorded during a normal cardiac cycle, during ventricular fibrillation, and during cardiac arrest. synchronous activation of both ventricles after atrial pacing, reduces presystolic mitral regurgitation, ${ }^{\mathrm{E} 30, \mathrm{E} 31}$ and produces only a marginal change in body oxygen uptake; ${ }^{\mathrm{E} 32, \mathrm{E} 33}$ the outcome results remain inconsistent. Experimental evaluation of this method with premature stimulation of the posterior wall area caused immediate shortening from transmural contraction but did not result in twisting (Video 4). A similar synchronous shortening effect may occur in the septum, which is adjacent to the RV electrode. Such sudden or premature septal shortening may reduce mitral insufficiency by moving this central septum structure into the midline, thereby geometrically offsetting the tethering of the mitral apparatus that exists during septal bulge stretching, which generates presystolic mitral insufficiency. Cardiac resynchronization therapy fails to restore twisting, and such inability to produce sequential contraction may explain why it fails to markedly improve body oxygen uptake or consistently enhance survival.

Knowledge of HVMB anatomy and the septum position of the bundle of His-Purkinje conducting system ${ }^{\mathrm{E} 34}$ allowed the develop- ment of the transmyocardial method to excite the conduction bundle along the surface of the descending segment of the apical loop (Figure 10). This novel approach immediately recovered normal pressure-dimension loops and restored normal sequential shortening and ventricular twisting motion (Figure E10; Video 5). ${ }^{35}$ Future direct placement techniques may exist from within the open ventricle (eg, if heart block follows aortic valve procedures for infected aortic cusps and annulus) or via transvenous approaches in patients with complete heart block. ${ }^{\mathrm{E} 35}$ These observations simply reinforce the recognition that novel application of knowledge about spatial anatomy and function relationships develop new interventions that positively improve cardiac performance.

\section{Conclusions}

The architectural background for standard observations of heart function were compared with several structural models. The resultant findings were most consistent with the HVMB model of Torrent-Guasp, whose dissection pattern confirms the conceptual 


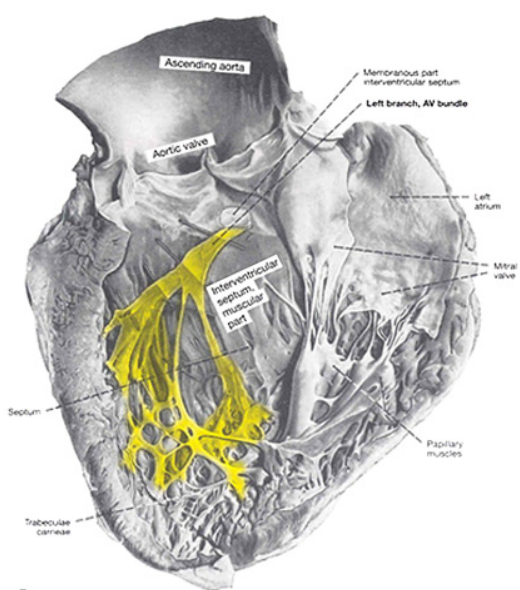

A

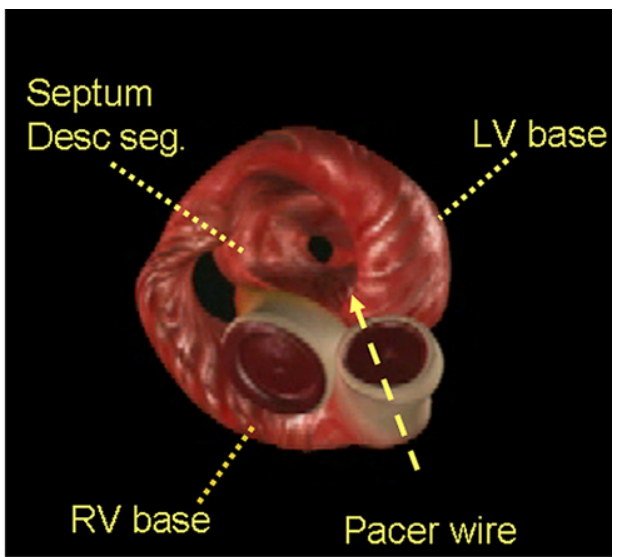

B
Figure 10. (A) Splay of His Purkinje fibers on the surface of the LV endocardium (descending segment) of the septum, as defined in the anatomic atlas of anatomy by Clemente. ${ }^{\mathrm{E} 34}$ (B) Trajectory of needle electrode placement into the high septum to stimulate septum pacing. The pathway was a needle insertion into the RV outflow tract, below the pulmonary valve, in a direction that traversed the septum and could withdraw blood from the LV. Needle withdrawal until no oxygenated blood return marked the site for electrode placement, as reported by Tomioka and colleagues. ${ }^{35} L V$, Left ventricle; $R V$, right ventricle. classic figure of 8 configuration described by the forefathers of anatomy and demonstrates functional preferential pathways that explain the observed directional and twisting sequential motions.

Application of this information allowed a unified concept of form to introduce rethinking of the mechanical factors causing the normal dynamic actions of normal hearts; showed differences between synchronous versus sequential beats; demonstrated that a muscular syncytium does not exist during systole in the heart; explained the fiber orientation and function of the septum; identified that "isovolumic diastolic relaxation" is an incorrect term; defined muscular reasons for ventricular suction and showed how novel treatments may relieve this event in the stunned heart; demonstrated the structure/function limitations of synchronous univentricular and biventricular pacing; and introduced a septum pacing concept producing sequential shortening that may have subsequent clinical application.

Further testing of these spatial anatomic concepts is needed, because the architectural coordination of structure and function, if properly confirmed, may answer in part Keith's ${ }^{\mathrm{E} 1}$ challenge during his Harvian Lecture in 1918, when he inquired, "How far does our knowledge of the function of the mammalian heart fall short of explaining its structure?" The natural concept of balance should apply to ventricular emptying and filling. Einstein indicated that "gravity and acceleration are equivalent," and Da Vinci stated that "heart blood is like tides; pulses are ebb and flow of ocean." Consequently, cardiac ejection and rapid filling should not be different.

\section{References}

1. Jung B, Markl M, Foll D, Buckberg GD, Hennig J. Investigating myocardial motion by MRI using tissue phase mapping. Eur J Cardiothorac Surg. 2006;29(Suppl 1):S150-7. Epub 2006 Mar 24.

2. Sengupta PP, Korinek J, Belohlavek M, Narula J, Vannan MA, Jahangir A, et al. Left ventricular structure and function: basic science for cardiac imaging. J Am Coll Cardiol. 2006;48:1988-2001.

3. Lorenz CH, Pastorek JS, Bundy JM. Delineation of normal human left ventricular twist throughout systole by tagged cine. J Cardiovasc Magn Reson. 2000;2:97-108.

4. Rademakers FE, Buchalter MB, Rogers WJ, Zerhouni EA, Weisfeldt ML, Weiss JL, et al. Dissociation between left ventricular untwisting and filling. Accentuation by catecholamines. Circulation. 1992; $85: 1572-81$
5. Sallin EA. Fiber orientation and ejection fraction in the human ventricle. Biophys J. 1969;9:954-64.

6. Macchiarelli G, Ohtani O. Endomysium in left ventricle. Heart. 2001; $86: 416$

7. Anderson RH, Siew YH, Sanchez-Quintana D, Redmann K, Lunkenheimer PP. Heuristic problems in defining the three-dimensional arrangement of the ventricular myocytes. Anat Rec. 2006;288A:579-86.

8. Grant RP. Notes on the muscular architecture of the left ventricle. Circulation. 1965;32:301-8.

9. Robb JS, Robb RC. The normal heart: anatomy and physiology of the structural units. Am Heart J. 1942;23:455-67.

10. Lev M, Simkins CS. Architecture of the human ventricular myocardium, technique for study using a modification of the Mall-MacCallum method. Lab Invest. 1956;8:306-409.

11. Rushmer RF, Crystal DK, Wagner C. The functional anatomy of ventricular contraction. Circ Res. 1953;1:162-70.

12. Ingels NB, Hansen D, Daughters GT II, Stinson EB, Alderman E, Miller DC. Relation between longitudinal, circumferential, and oblique shortening and torsional deformation in the left ventricle of the transplanted human heart. Circ Res. 1989;64:915-27.

13. Streeter DD Jr, Spotnitz HM, Patel DP, Ross J Jr, Sonnenblick EH. Fiber orientation in the canine left ventricle during diastole and systole. Circ Res. 1969;24:339-47.

14. Chen J, Song SK, Liu W, McLean M, Allen JS, Tan J, et al. Remodeling of cardiac fiber structure after infarction in rats quantified with diffusion tensor MRI. Am J Physiol Heart Circ Physiol. 2003;285:H946-54.

15. Greenbaum RA, Ho SY, Gibson DG, Becker AE, Anderson RH. Left ventricular fibre architecture in man. Br Heart J. 1981;45:248-63.

16. Streeter DD Jr. Gross morphology and fiber geometry of the heart. In Berne RM, ed. Handbook of Physiology. Baltimore: Williams and Wilkins; 1979:61-112.

17. Torrent-Guasp F. Sobre morfologia y funcionalismo cardiacos. Rev Esp Cardiol. 1967;20:14

18. Torrent-Guasp F, Buckberg GD, Clemente C, Cox JL, Coghlan HC, Gharib $\mathrm{M}$. The structure and function of the helical heart and its buttress wrapping. I. The normal macroscopic structure of the heart. Semin Thorac Cardiovasc Surg. 2001;13:301-19.

19. Zhukov L, Barr AH. Heart-muscle fiber reconstruction from diffusion tensor MRI. VIS. 2003;597-602.

20. Bogaert J, Rademakers FE. Regional nonuniformity of normal adult human left ventricle. Am J Physiol Heart Circ Physiol. 2001;280:H610-20.

21. Torrent-Guasp F, Kocica MJ, Corno A, Komeda M, Cox J, Flotats A, et al. Systolic ventricular filling. Eur J Cardiothorac Surg. 2004;25: 376-86.

22. Buckberg GD, Castella M, Gharib M, Saleh S. Structure/function interface with sequential shortening of basal and apical components of the myocardial band. Eur J Cardiothorac Surg. 2006;29(Suppl 1):S75-97. 
23. Katz AM, Zile MR. New molecular mechanism in diastolic heart failure. Circulation. 2006;113:1922-5.

24. Korinek J, Kjaergaard J, Sengupta PP, Yoshifuku S, McMahon EM, Cha SS, et al. High spatial resolution speckle tracking improves accuracy of 2-dimensional strain measurements: an update on a new method in functional echocardiography. $J$ Am Soc Echocardiogr. 2007;20:165-70.

25. Liakopoulos O, Tomioka H, Buckberg GD, Tan Z, Hristov N, Trummer G. Sequential Deformation and physiological considerations in unipolar right or left ventricular pacing. Eur J Cardiothorac Surg. 2006;29(Suppl 1):S188-97.

26. Torrent-Guasp F, Buckberg GD, Clemente C, Cox JL, Coghlan HC, Gharib M. The structure and function of the helical heart and its buttress wrapping. I. The normal macroscopic structure of the heart. Semin Thorac Cardiovasc Surg. 2001;13:301-19.

27. Rohmer D SAGG. Reconstruction and visualization of fiber and sheet structure with regularized tensor diffusion MRI in the human heart. E O Lawrence National Berkley Laboratory Publications 2006;(LNBL-60277):1-18.

28. Saleh S, Liakopoulos O, Buckberg GD. The septal motor of biventricular function. Eur J Cardiothorac Surg. 2006;29(Suppl 1):S126-38. Epub 2006 Mar 27
29. Armour JA, Randall WC. Electrical and mechanical activity of papillary muscle. Am J Physiol. 1970;218:1710-7.

30. Athanasuleas CL, Stanley AWH Jr, Buckberg GD. Restoration of contractile function in the enlarged left ventricle by exclusion of remodeled akinetic anterior segment: Surgical strategy, myocardial protection, and angiographic results. J Card Surg. 1998;13: 418-28.

31. Brutsaert DL, Stanislas U, Gillibert TC. Diastolic failure: pathophysiology and therapeutic implications. J Am Coll Cardiol. 1993;22:318-25.

32. Helmes M, Trombitas K, Granzier H. Titin develops restoring force in rat cardiac myocytes. Circ Res. 1996;79:619-26.

33. Bell SP, Nyland L, Tischler MD, McNabb M, Granzier H, LeWinter MM. Alterations in the determinants of diastolic suction during pacing tachycardia. Circ Res. 2000;87:235-40.

34. Castella M, Buckberg GD, Saleh S. Diastolic dysfunction in stunned myocardium: a state of abnormal excitation-contraction coupling that is limited by $\mathrm{Na}+-\mathrm{H}+$ exchange inhibition. Eur J Cardiothorac Surg. 2006;29(Suppl 1):S107-14.

35. Tomioka H, Liakopoulos O, Buckberg GD, Hristov N, Tan Z, Trummer G. The effect of ventricular sequential contraction on helical heart during pacing. Eur J Cardiothorac Surg. 2006;29(Suppl 1): S198-206. Epub 2006 Mar 24. 


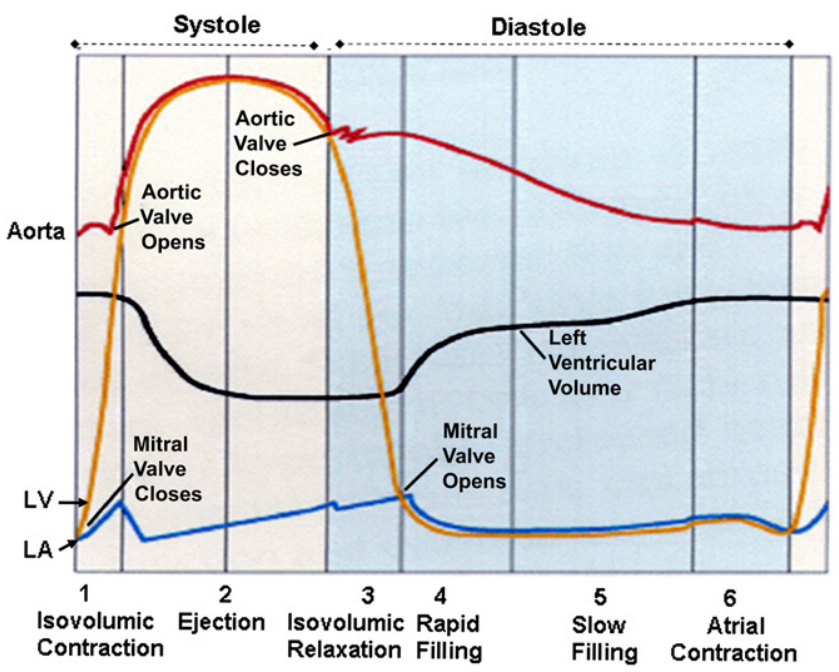

Figure E1. Currently accepted time frames of systole and diastole, with measurements of intravascular pressure in the aorta, LV, left atrium, and LV volume, together with their impact on the mitral and aortic valves. The physiologic phases of the cardiac cycle, including contraction, ejection, and relaxation (questioned in this report). Rapid and slow filling and atrial contraction are shown. $L V$, Left ventricle; $L A$, left atrium. 

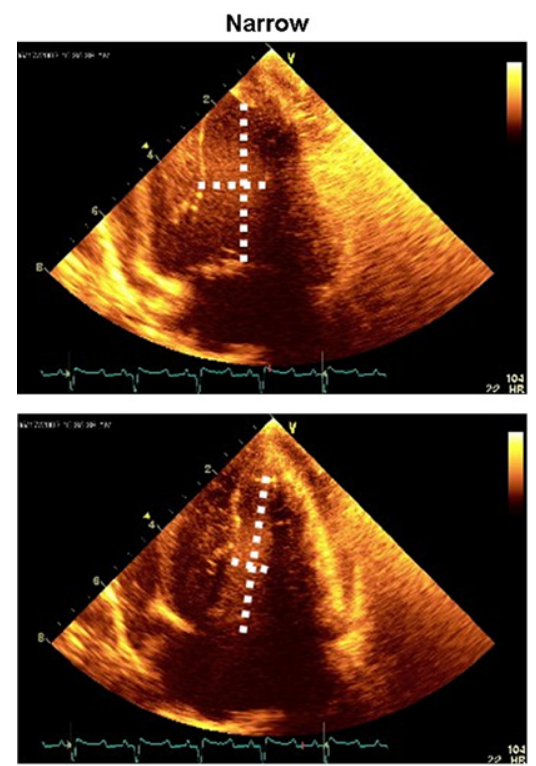

Lengthen
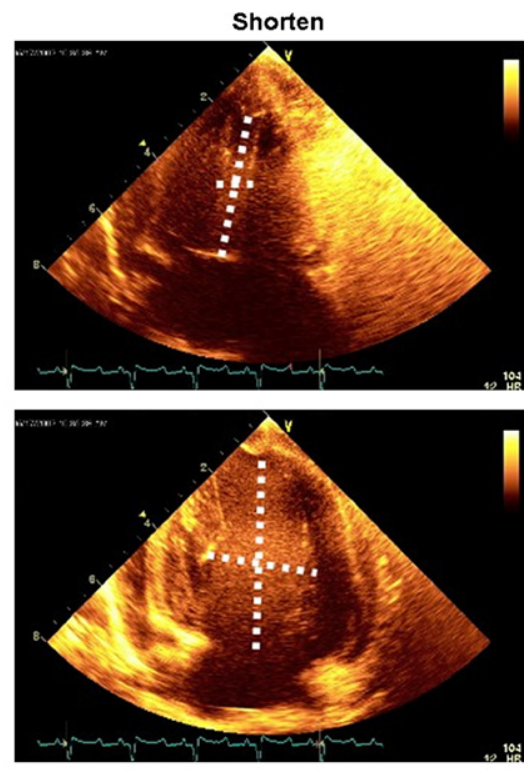

Widen
Figure E2. Two-dimensional images showing the normal sequence of narrowing, shortening, lengthening, and widening of the ventricular cavity during a normal cardiac cycle. Images were obtained by epicardial imaging in an open chest porcine preparation. Note progressive muscular thickening (evaluated by wider distance between epicardial and endocardial lines as myocardial mass narrows and shortens for ejection), together with maintained thickness as heart lengthens during the rapid filling phase before substantial widening. 

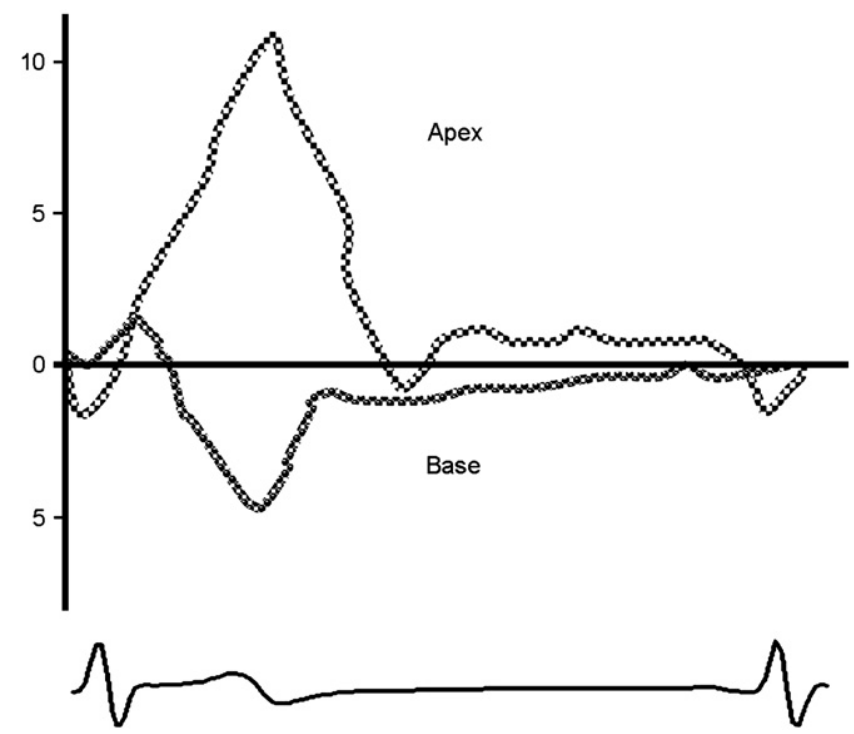

Figure E3. Twist of the heart: Clockwise (below baseline) and counterclockwise (above baseline) twists of the base and apex, respectively, during the cardiac ejection and filling periods are represented in rotational degrees using speckle tracking (Echopac PC V 6, GE Healthcare, Milwaukee, Wis). The relationships between the initial uniform and reciprocal twisting motions of the base and apex during the pre-ejection, ejection, and rapid and slow filling periods are explained in the text. SE, Standard error. 

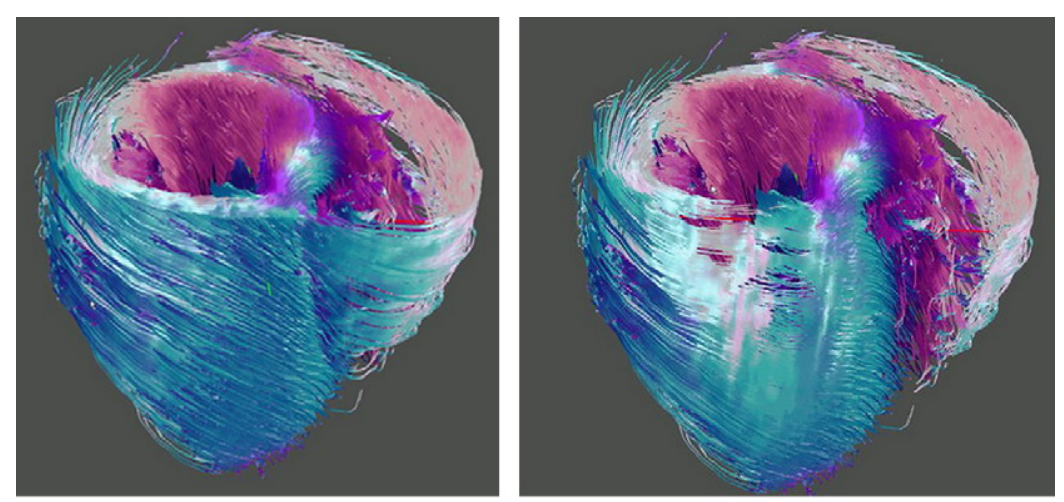

Figure E4. Diffusion tensor MRI from the work of Zhukov and Barr ${ }^{19}$ showing the helical inner or endocardial (clockwise) and outer or epicardial (counterclockwise) fiber orientation (purple and blue colors) and a central LV free wall in the upper chamber that is white to reflect a more horizontal or small angle pitch that does not involve the septum.
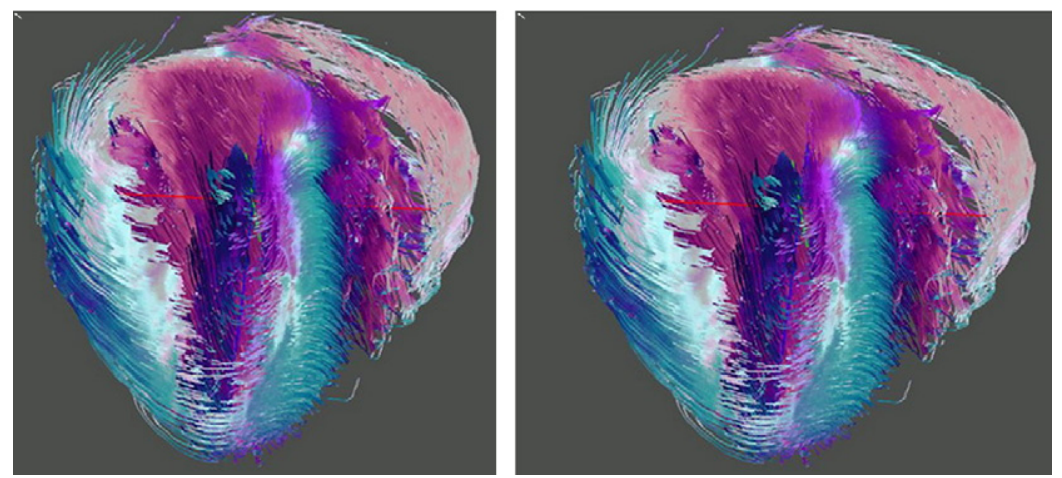


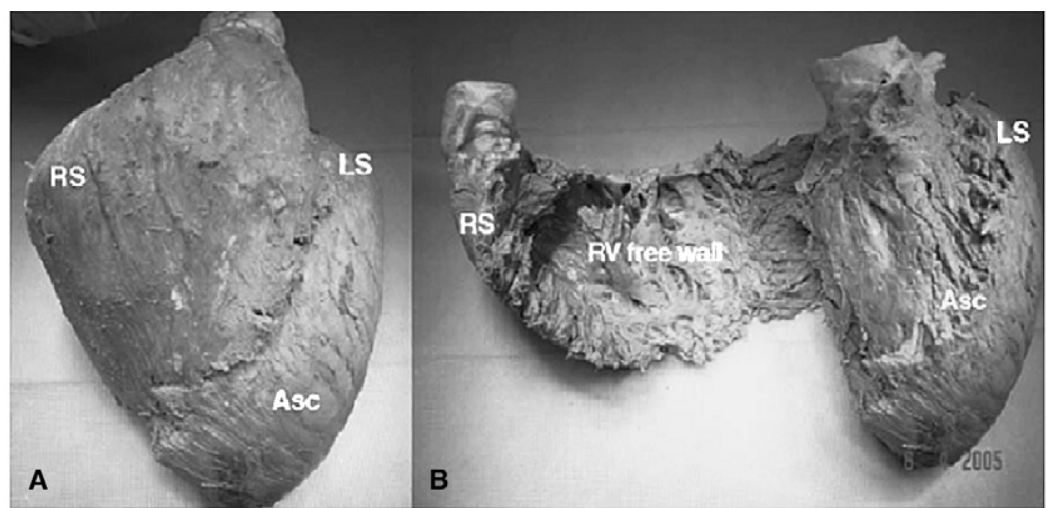

A
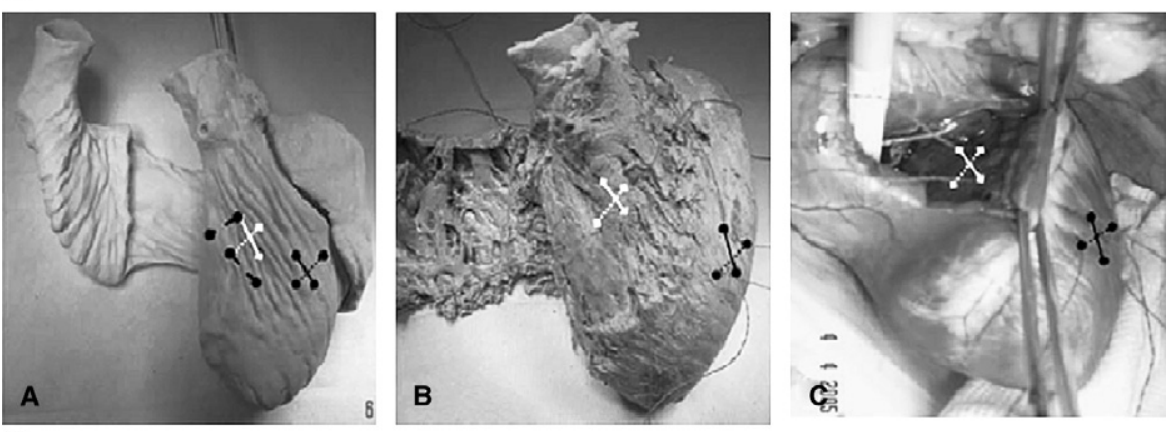

Figure E5. A, Anatomic preparations showing the orientation of the ventricular myocardial band of the (A) intact heart and $(B)$ after exposing the septum by unfolding the RV free wall. Note the similar configuration of the septum and LV free wall composed of the ascending segment of apical loop. B, Helical heart model (A), anatomic specimen (B), and experimental study (C) of the septum and LV free wall to demonstrate sonomicrometer crystal positioning. Crystal orientation was in the direction of maximal segmental shortening of descending $(0-O)$ and ascending segments $\left(\mathrm{O}_{-} \mathrm{O}\right)$ of $\mathrm{LV}$ free wall and septum descending ( $\square-\square)$ and ascending segments $(\square-\square)$, and placed in a perpendicular direction (O- - ) to septal maximal segmental shortening (A). RS, Right segment of basal loop; $L S$, left segment of basal loop; Asc, ascending segment of apical Ioop; $R V$, right ventricle.

B 

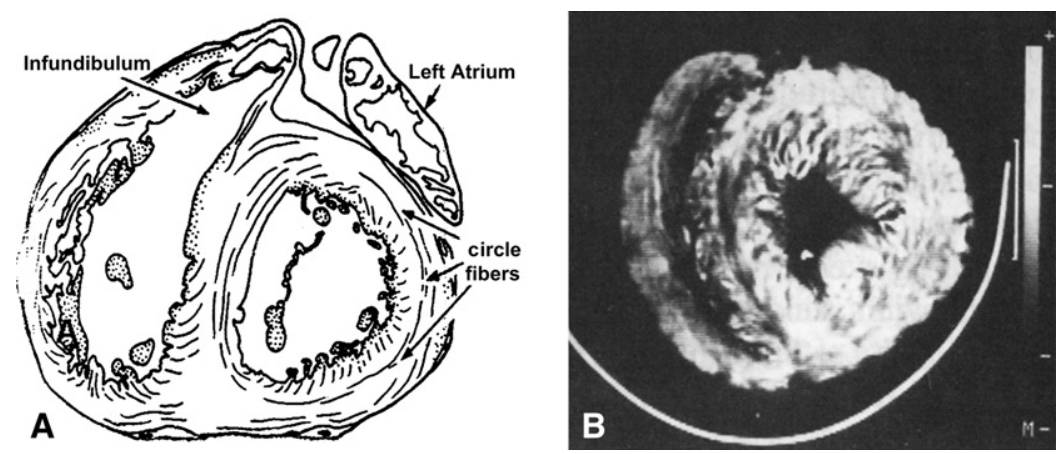

Figure E6. A Cross-section images demonstrating the oblique criss-cross endocardial and epicardial fibers contained within a circumferential midseptal wall. B, Computed tomography scans demonstrating the interweaving collagen support of the connective tissue skeleton that is likely the scaffold for reciprocally oblique septal muscular fibers. Note the space between the 2 septum regions. 


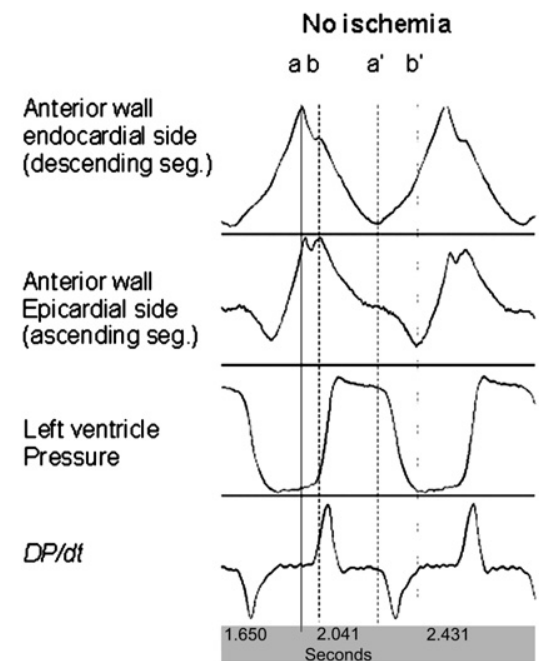

A

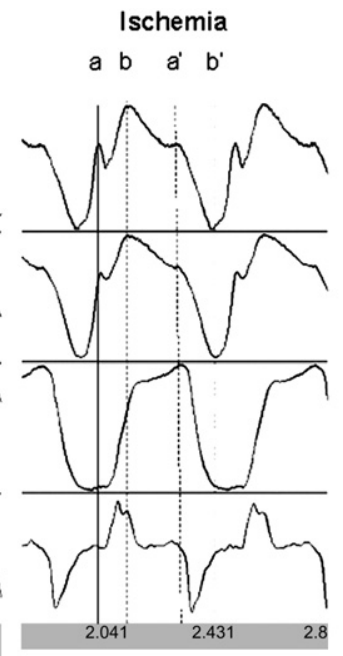

B

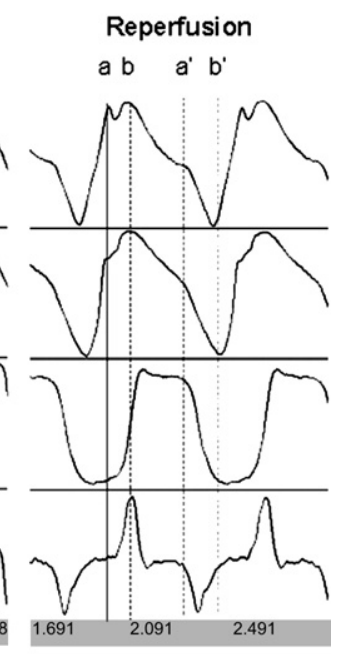

C
Figure E7. Tracings of myocardial segment lengths, LV pressure, and $\mathrm{dP} / \mathrm{dt}$ of a single animal with no pretreatment, before ischemia $(A)$, during 15 minutes of left anterior descending occlusion (B), and after 60 minutes of left anterior descending reperfusion (C). Note the earlier start (line a) and finish (line a') of contraction of the endocardial side compared with the epicardial side (lines $b$ and $b^{\prime}$ ) before ischemia and how this coordination disappears during reperfusion, with a delayed contraction extending into diastole. This effect is more evident in the endocardial side. Time coordinates $(x)$ are in the same scale in all tracings, but scales of segment length coordinates ( $y$ ) change to better show the times of start and finish contraction. 


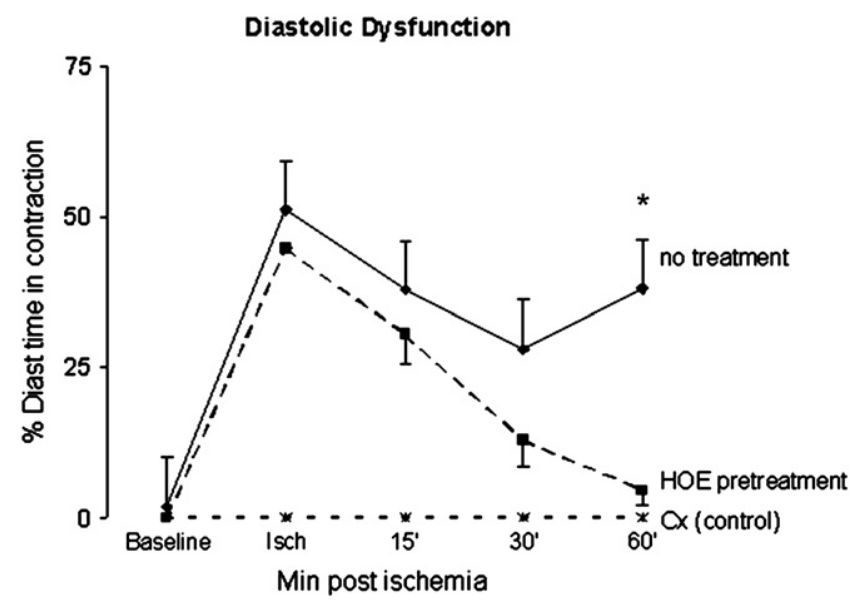

Figure E8. Diastolic dysfunction: Percentage of diastole in which prolonged endocardial contraction was detected, so that this extension persisted without sodium hydrogen exchange inhibitor (HOE) treatment and returned toward normal (no extension) during the 1-hour observation interval. Values expressed as mean \pm standard error of the mean. ${ }^{*} P<.05$ HOE pretreatment vs no treatment). 


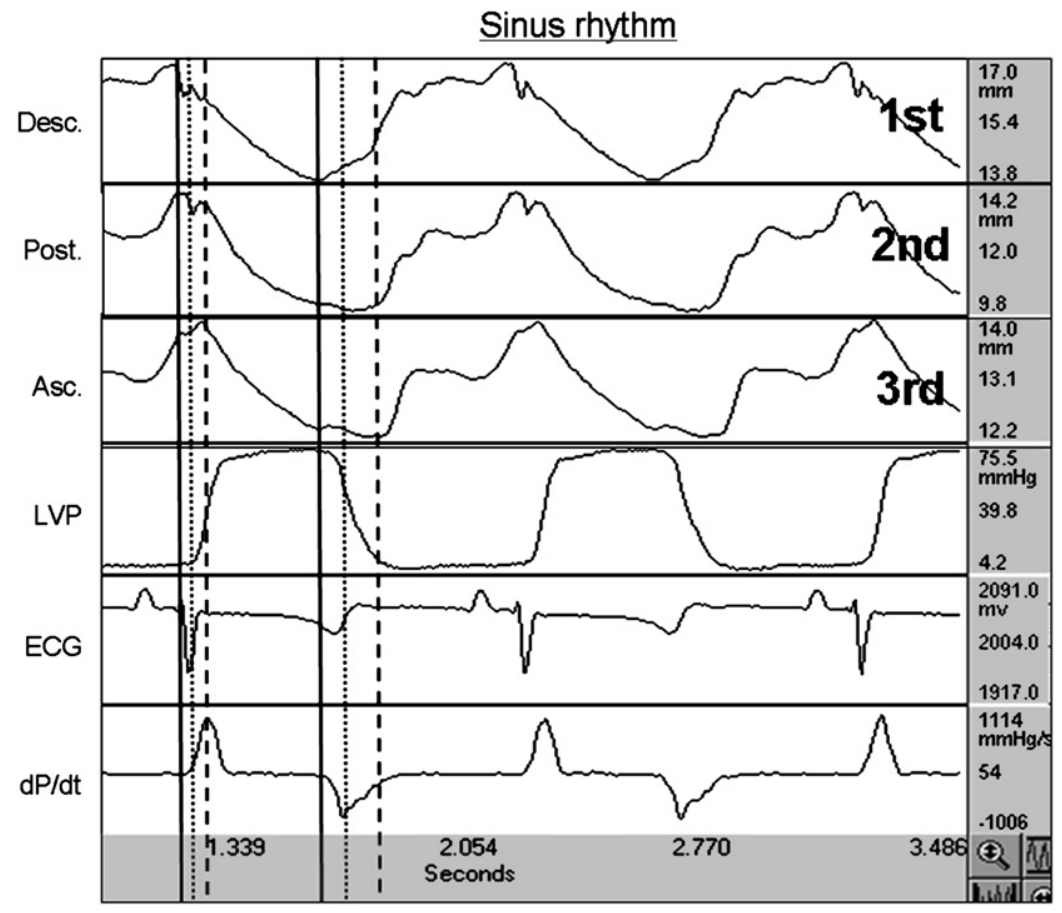

Figure E9. Simultaneous recordings of sequential shortening of the descending, posterior, and ascending segments during normal sinus rhythm. Note the normal sequence of shortening starts with shortening of the descending segment (DESC) corresponding to early slow LV pressure increase, followed by the posterior LV wall shortening $14 \pm 8 \mathrm{~ms}$ later, (POST) and finally LV ascending segment (ASC) shortening corresponding with peak positive $\mathrm{dP} / \mathrm{dt}$ wave $86 \pm 14 \mathrm{~ms}$ after shortening of the descending segment. The end of shortening showed a pattern similar to the end of shortening first at the descending segment, followed by the posterior segment and then the ascending segment. Marking lines indicate the start and end of shortening in the descending segment (solid line), posterior wall (punctuated line), and ascending segment (hatched line). LVP, Left ventricular pressure; ECG, electrocardiogram; $d P / d t$, first derivate of LVP. 


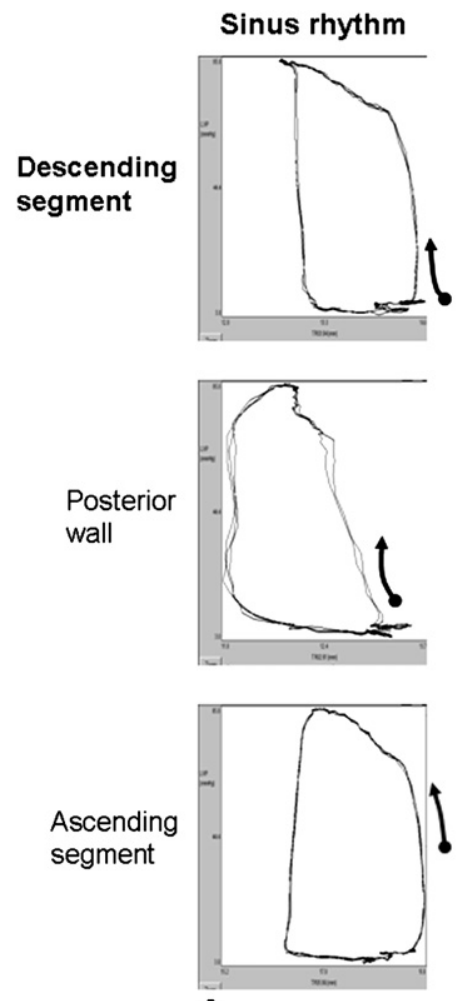

A
Atrio biventricular
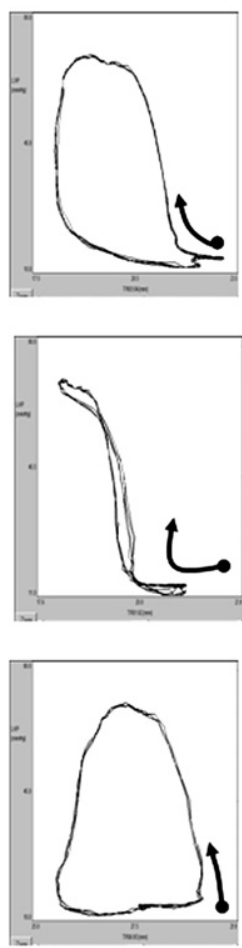

B
Atrio-High septal
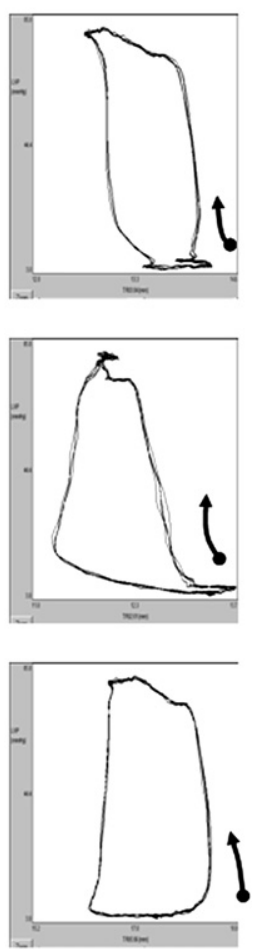

C
Figure E10. Comparison of the pressure-dimension loops of the descending, posterior, and ascending segments during normal sinus rhythm in atriobiventricular and atrioseptal pacing. The longitudinal axis expresses LV pressure $(\mathrm{mm}$ $\mathrm{Hg}$ ), and the horizontal axis is the segment length (mm). Note that pressure-dimension loops during normal sinus rhythm (A) and atrial septal pacing (C) show a similar pattern, with the start of contraction of the descending segment at the beginning of the initial slow increase of $L V$ pressure, followed by the start of shortening of the LV posterior wall segment, and finally the start of contraction of the ascending segment at the end of LV pressure increase during the systolic ejection phase of the ventricle. Conversely, early posterior stimulation during biventricular pacing (B) shows marked desynchronization of this region with loop volume loss during this absence of sequencing. 


\section{Online References}

E1. Keith A. The functional anatomy of the heart. Br Med J. 1918;1:361-3.

E2. Tibayan FA, Lai DT, Timek TA, Dagum P, Liang D, Daughters GT, et al. Alterations in left ventricular torsion in tachycardia-induced dilated cardiomyopathy. J Thorac Cardiovasc Surg. 2002;124:43-9.

E3. Shapiro EP, Rademakers FE. Importance of oblique fiber orientation for left ventricular wall deformation. Technol Health Care. 1997;5:21-8.

E4. Spotnitz HM. Macro design, structure, and mechanics of the left ventricle. J Thorac Cardiovasc Surg. 2000;119:1053-77.

E5. Lunkenheimer PP, Muller RP, Konermann CHR, Lunkenheimer A, Kohler P. Architecture of the myocardium in computer-tomography. Invest Radiol. 1984;19:271-8.

E6. Frank O. Isometrie und Isotonie des Herzmuskels. Ztschr Biol. 2007;41:14-34.

E7. Krehl L. Kenntniss der fallung und entleerung des herzens. Abhandl Math Phys. 1891;29:341-62.

E8. MacCallum JB. On the muscular architecture and growth of the ventricles of the heart. Johns Hopkins Hosp Rep. 1900;9:307-35.

E9. Jouk PS, Usson Y, Michalowicz G, Grossi L. Three-dimensional cartography of the pattern of the myofibres in the second trimester fetal human heart. Anat Embryol (Berl). 2000;202:103-18.

E10. Lunkenheimer PP, Redmann K, Westermann P, Rothaus K, Cryer CW, Niederer $\mathrm{P}$, et al. The myocardium and its fibrous matrix working in concert as a spatially netted mesh: a critical review of the purported tertiary structure of the ventricular mass. Eur J Cardiothorac Surg. 2006;29(Suppl 1):S41-9.

E11. Torrent-Guasp F. Anatomia Funcional del Corazon. Madrid: Paz Montalvo 1957;11-94

E12. Waldman LK, Nosan D, Villarreal F, Covell JW. Relation between transmural deformation and local myofiber direction in canine left ventricle. Circ Res. 1988;63:550-62.

E13. Rigden J. Einstein 1905: The Standard of Greatness. Cambridge, MA: Harvard University Press; 2005.

E14. Ormiston JA, Shah PM, Tei C, Wong M. Size and motion of the mitral valve annulus in man. I. A two-dimensional echocardiographic method and findings in normal subjects. Circulation. 1981;64:113-20.

E15. Tibayan FA, Lai DT, Timek TA, Dagum P, Liang D, Daughters GT, et al. Alterations in left ventricular torsion in tachycardia-induced dilated cardiomyopathy. J Thorac Cardiovasc Surg. 2002;124:43-9.

E16. Sodi-Pallares D, Calder RM. New Bases of Electrocardiography. St Louis: Mosby 1956

E17. Moon MR, Ingels NB, Daughters GT II, Stinson EB, Hansen DE, Miller DC. Alterations in left ventricular twist mechanics with inotropic stimulation and volume loading in human subjects. Circulation. 1994;89:142-50.

E18. Castella M, Buckberg GD, Saleh S, Gharib M. Structure function interface with sequential shortening of basal and apical components of the myocardial band. Eur J Cardiothorac Surg. 2005;27:980-7.

E19. Lunkenheimer PP, Redmann K, Anderson RH. The architecture of the ventricular mass and its functional implications for organ-preserving surgery. Eur J Cardiothorac Surg. 2005;27:183-90.
E20. Wiggers CJ. The muscular reactions of the mammalian ventricles to artificial surface stimuli. Am J Physiol. 1925;73:346-78.

E21. Weber EH. Hilderbrand's Handbuch der Anatomie des Menschen. 4th Ed. Leipzig 1831.

E22. Torrent-Guasp F, Whimster WF, Redmann K. A silicone rubber mould of the heart. Technol Health Care. 1997;5:13-20.

E23. Bernard C. An Introduction to the Study of Experimental Medicine. New York: Dover Publications; 1957.

E24. Brutsaert DL, Stanislas U, Gillibert TC. Diastolic failure: pathophysiology and therapeutic implications. J Am Coll Cardiol. 1993;22: $318-25$.

E25. Brutsaert DL, Szoka FC. Relaxation and diastole of the heart. Physiol Rev. 1989;69:1228-315.

E26. Follath F, Cleland JGF, Kivikko M, Sarapohja T, Sandell EP. Comparison of the effect of concomitant beta-blocking treatment on the symptomatic responses to levosimendan and dobutamine in patients with severe low-output heart failure. J Card Fail. 2004; 10:S120.

E27. Bursi F, Weston SA, Redfield MM, Jacobsen SJ, Pakhomov S, Nkomo VT, et al. Systolic and diastolic heart failure in the community. JAMA. 2006;296:2209-16.

E28. Pitzalis MV, Iacoviello M, Romito R, Guida P, De Tommasi E, Luzzi $\mathrm{G}$, et al. Ventricular asynchrony predicts a better outcome in patients with chronic heart failure receiving cardiac resynchronization therapy. J Am Coll Cardiol. 2005;45:65-9.

E29. Sassara M, Achilli A, Bianchi S, Ficili S, Marullo A, Pontillo D, et al Long-term effectiveness of dual site left ventricular cardiac resynchronization therapy in a patient with congestive heart failure. Pacing Clin Electrophysiol. 2004;27(6 Pt 1):805-7.

E30. Breithardt OA, Sinha AM, Schwammenthal E, Bidaoui N, Markus KU, Franke A, et al. Acute effects of cardiac resynchronization therapy on functional mitral regurgitation in advanced systolic heart failure. $J \mathrm{Am}$ Coll Cardiol. 2003;41:765-70.

E31. Cleland JG, Daubert JC, Erdmann E, Freemantle N, Gras D, Kappenberger $\mathrm{L}$, et al. The effect of cardiac resynchronization on morbidity and mortality in heart failure. $N$ Engl J Med. 2005;352: 1539-49.

E32. Abraham WT, Young JB, Leon AR, Adler S, Bank AJ, Hall SA, et al. Effects of cardiac resynchronization on disease progression in patients with left ventricular systolic dysfunction, an indication for an implantable cardioverter-defibrillator, and mildly symptomatic chronic heart failure. Circulation. 2004;110:2864-8.

E33. Auricchio A, Stellbrink C, Sack S, Block M, Vogt J, Bakker P, et al Long-term clinical effect of hemodynamically optimized cardiac resynchronization therapy in patients with heart failure and ventricular conduction delay. J Am Coll Cardiol. 2002;39:2026-33.

E34. Clemente C. Anatomy: A Regional Atlas of the Human Body. 4 ed. Lippincott, Williams \& Wilkins 1997.

E35. Karpawich PP, Gates J, Stokes KB. Septal His-Purkinje ventricular pacing in canines: a new endocardial electrode approach. Pacing Clin Electrophysiol. 1992;15(11 Pt 2):2011-5. 